\title{
Cactaceae endémicas del Perú
}

\author{
Mónica Arakaki ${ }^{1}$, Carlos Ostolaza $^{2}$, Fátima Cáceres ${ }^{3}$ y José Roque ${ }^{4}$
}

1 Department of Botany, University of Florida Gainesville, PO Box 118526, Gainesville, FL 32611-8526.

marakaki@lycos.com

2 Sociedad Peruana de Cactus y Suculentas, Aptdo. 3215, Lima 100, Perú.

carlosto@ec-red.com

${ }^{3}$ Universidad Nacional de San Agustín, Av. Alcides Carrión s/n, Pab. Biología 2do. Piso, Arequipa, Perú. facahu60@hotmail.com

${ }^{4}$ Museo de Historia Natural, Av. Arenales 1256, Aptdo. 14-0434, Lima 14, Perú.

peperoque@yahoo.com

\section{Resumen}

La familia Cactaceae es reconocida en el Perú por presentar 43 géneros y alrededor de 250 especies (Brako \& Zarucchi, 1993; Ulloa Ulloa et al., 2004), mayormente cactus arbustivo-columnares. En este trabajo reconocemos 199 endemismos en 32 géneros. Seis géneros, Calymnanthium, Lasiocereus, Matucana, Mila, Oroya y Pygmaeocereus son endémicos al Perú. Esta familia requiere de esfuerzos metódicos para incrementar su representación en los herbarios nacionales, asociados con una evaluación de las poblaciones y de sus hábitats, así como una evaluación de la taxonomía y sistemática de estos taxones. La mayoría de los taxones endémicos ocupan las regiones Matorral Desértico y Mesoandina, desde el nivel del mar hasta los $4000 \mathrm{~m}$ de altitud. Se aplicaron las categorías y criterios de la UICN a 58 taxones. Quince taxones endémicos están representados dentro del Sistema Nacional de Áreas Naturales Protegidas por el Estado.

Palabras claves: Cactaceae, Calymnanthium, Lasiocereus, Matucana, Mila, Oroya, Pygmaeocereus, Perú, endemismo, plantas endémicas.

\section{Abstract}

The Cactaceae are represented in Peru by 43 genera and nearly 250 species (Brako \& Zarucchi, 1993; Ulloa Ulloa et al., 2004), mostly erect-columnar or sprawling cactus. Here we recognize 1999 endemic taxa in 32 genera. Six genera-Calymnanthium, Lasiocereus, Matucana, Mila, Oroya and Pygmaeocereus- are endemic to Peru. This family requires methodic efforts to increase the number of vouchers in national herbaria, as well as evaluations of the populations, habitats, taxonomy and systematics of these taxa. Most endemic taxa are found in the Desert Shrubland and Mesoandean regions, from sea level to 4000 m elevation. We applied IUCN categories and criteria to 58 taxa. Fifteen endemic taxa have been recorded in the Peruvian parks system.

Keywords: Cactaceae, Calymnanthium, Lasiocereus, Matucana, Mila, Oroya, Pygmaeocereus, Peru, endemism, endemic plants.

\section{Armatocereus arduus F. Ritter}

\section{DD}

Publicación: Kakteen Sudamer. 4: 1271. 1981.

Colección tipo: F. Ritter 1060

Herbarios: U, ZSS.

Nombre común: D esconocido.

Registro departamental: CA, LL.

Regiones Ecológicas: BS; $1000-1500 \mathrm{~m}$.

SINAN PE: Sin registro.

Hemarios peruanos: Ninguno.

Observaciones: Cactus arborescente, de hasta $8 \mathrm{~m}$ de alto, conocido solamente de la cuenca del nío Marañón. Especie poco estudiada y recolectada, de estatus taxonómico incierto. La información disponible es insuficiente para determinar el estado de conservación de esta especie.

\section{Armatocereus ghiesbreghtii (K. Schum.) F. Ritter}

\section{NE}

Publicación: Backeberg's D escr. \& Eroert. taxon. nomenkl. Fragen [unpaged]. 1961.

Colección tipo: D esconocido. s.n.

Herbarios:

Nombre común: D esconocido.

Registro departamental: AN, AR, CA, HV, IC, LL, LI.

Regiones Ecológicas: MDE, MA; $1000-3000$ m.

SINANPE: PNH

Herbarios peruanos: HUSA (1).
Observaciones: Cactus arborescente, conocido de más de 10 localidades. Hunt (1999) no reconoce la especie debido a que el tipo podría proceder de México y la descripción se basaba en una planta cultivada. Anderson (2001) lo incluye con reserva en A rmatocereus laetus.

\section{Armatocereus mataranus F. Ritter subsp. ancashensis Ostolaza \\ DD}

Publicación: Cactaceae Consensus Initiatives, 6: 8. 1998. Colección tipo: F. Ritter 672a

Hemarios: U, SG O, ZSS.

Nombre común: D esconocido.

Registro departamental: AN.

Regiones Ecológicas: MDE; 2000- $2500 \mathrm{~m}$.

SINAN PE: Sin registro.

Herbarios peruanos: Ninguno.

Observaciones: Cactus arborescente de hasta $7 \mathrm{~m}$ de alto. Este taxón es conocido, al parecer, sólo de la localidad tipo, en laderas situadas al lado oriental de la Cordillera Blanca. Anderson (2001) sugiere que puede no ser distinta a A rmatocereus laetus, la cual se halla en Ecuador.

Nota del Editor: En la versión on line de este artículo han sido omitidos los mapas del Perú que ilustraban el Registro departamental. Para ubicar las abreviaturas de los departamentos vea al final del artículo. 


\section{Armatocereus mataranus F. Ritter}

DD

Publicación: Succulenta (Netherlands) 46(2): 23, [illus.]. 1967.

Colección tipo: F. Ritter 672

Herbarios: U, ZSS.

Nombre común: D esconocido.

Registro departamental: CA.

Regiones Ecológicas: MDE; 2000- 2500

m.

SINAN PE: Sin registro.

Herbarios peruanos: Ninguno.

Observaciones: Este cactus arborescente ha sido poco estudiado. Su taxonomía y nombre son inciertos (Anderson, 2001). Probablemente sea coespecifico con A rmatocereus laetus, una especie conocida también de Ecuador. Plantas con este nombre se encuentran en cultivo en el Jardín Botánico Particular de San Marcos en Cajamarca.

\section{Armatocereus procerus Rauh \& Backeb.}

\section{LC}

Publicación: Cactus (Paris) 51: 95. 1956.

Colección tipo: W. Rauh K 32

Herbarios: ZSS.

Nombre común: D esconocido.

Registro departamental: AN, IC, LI.

Regiones Ecológicas: D ST; $500-1000$

$\mathrm{m}$

SINAN PE: Sin registro.

Herbarios penuanos: USM (6).

Observaciones: Este cactus arborescente fue descrito de un ejemplar recolectado por Rauh, del que Eggli (1987) menciona lleva datos diferentes de localidad que incluye de Ancash a Ica. Esta especie se conoce de varias localidades aisladas a lo largo de la costa de Lima e Ica.

\section{Armatocereus rauhii Backeb. subsp. balsasensis Ostolaza}

\section{VU, Bla}

Publicación: Cactaceae Consensus Initiatives, 6: 8. 1998

Colección tipo: F. Ritter 273a

Herbarios: U, SG O, ZSS.

Nombre común: Desconocido.

Registro departamental: AM, CA, LA.

Regiones Ecológicas: MDE, BS; 800$1500 \mathrm{~m}$.

SINANPE: Sin registro.

Herbarios peruanos: USM (3).

Observaciones: Cactácea arborescente de hasta $10 \mathrm{~m}$. Las poblaciones observadas de este cactus arbóreo se encuentran en laderas de difícil acceso, en áreas con poco desarrollo urbano. O stolaza (1997) reporta la existencia de un buen número de poblaciones de esta especie, pero cada una con menos de 2500 individuos. Se halla en cultivo en un jardín botánico privado en Cajamarca.

\section{Armatoceneus rauhii Backeb.}

\section{LC}

Publicación:

Colección tipo: W. Rauh K127

Herbarios: ZSS.

Nombre común: D esconocido.

Registro departamental: AM, AN, CA.

Regiones Ecológicas: MDE, BS; 1000$1500 \mathrm{~m}$.

SINANPE: Sin registro.

Herbarios peruanos: Ninguno.

Observaciones: Este cactus arbóreo está igualmente distribuido en el norte del país, ocupando laderas y matorrales en la vertiente occidental andina. Esta subespecie se conoce de la cuenca del Huancabamba.

\section{Armatocereus niomajensis Rauh \& Backeb.}

\section{NE}

Publicación: Descr. Cact. Nov. 13. [1957] 1956.

Colección tipo: W. Rauh K152a

Herbarios: HEID?.

Nombre común: D esconocido.

Registro departamental: AR.

Regiones Ecológicas: MDE; $2600 \mathrm{~m}$.

SINANPE: RPSC

Herbarios peruanos: HUSA (3).

Observaciones: Cactus arbustivo de hasta $2 \mathrm{~m}$ de alto, conocido solamente para Arequipa, de la cuenca del Cotahausi, en laderas rocosas. Brako \& Zarucchi (1993) la listaron como sinónimo de A rmatocereus ghiesbreghtii, criterio que no se acepta aquí.

\section{Armatoceneus rupicola F. Ritter}

DD

Publicación: Kakteen Sudamer. 4: 1278. 1981. Colección tipo: F. Ritter 1318

Herbarios: SG O, U.

Nombre común: Desconocido.

Registro departamental: CA.

Regiones Ecológicas: MDE; 2000- $2500 \mathrm{~m}$.

SINANPE: Sin registro.

Herbarios peruanos: Ninguno.

Observaciones: Cactus arborescente conocido de una localidad en Cajamarca. Probablemente sea coespecífica con A rmatocereus mataranus (Anderson, 2001). La información es insuficiente para realizar una evaluación de su estado de conservación.

\section{Austrocylindropuntia pachypus (K. Schum.) Backeb.}

$$
\text { EN, B1a; D }
$$

Publicación: Cactaceae (Berlin) 1941, pt. 2: 13. 1942.

Colección tipo: A. Weberbauer s.n.

Herbarios: SG O, ZSS.

Nombre común: D esconocido.

Registro departamental: AN, LI.

Regiones Ecológicas: D ST; 0-500 m.

SINANPE: Sin registro.

Herbarios peruanos: USM (2).

Observaciones: Este cactus arborescente ha sido encontrado solamente en la vertiente occidental, en laderas y planicies de Ancash y Lima. Brako \& Zarucchi (1993) la incluyeron como sinónimo de 0 puntia pachypus. 


\section{Browningia albiceps F. Ritter}

\section{DD}

Publicación: Kakteen Sudamer. 4(1): 1322. 1981.

Colección tipo: F. Ritter 1319

Herbarios: SG O, U.

Nombre común: D esconocido.

Registro departamental: CA.

Regiones Ecológicas: MDE; $1000-1500$

m.

SINAN PE: Sin registro.

Herbarios peruanos: Ninguno.

Observaciones: Cactus arborescente de hasta $5 \mathrm{~m}$ de alto, de posición taxonómica incierta (Anderson, 2001). De esta especie se desconoce las estructuras reproductivas y semillas.

\section{Browningia altissima Buxb.}

\section{LC}

Publicación: Kakteen Sudamer. 4(1): 104. 1964.

Colección tipo: F. Ritter 291

Herbarios: ZSS

Nombre común: D esconocido.

Registro departamental: CA.

Regiones Ecológicas: BS; 0-500 m.

SINAN PE: Sin registro.

Herbarios peruanos: USM (1).

Observaciones: Cactus arborescente de hasta $10 \mathrm{~m}$ de alto, ha sido encontrado solamente en la vertiente occidental, al norte del país. En cultivo en el Jardín Botánico San Marcos (Cajamarca).

\section{Browningia amstutziae (Rauh \& Backeb.) Hutchison ex Buxb.}

\section{DD}

Publicación: in Krainz, Kakteen, Lief. 31 \& 32, Gen. C iv/ I. (Nov. 1965), in obs. 1965.

Colección tipo: W. Rauh K5

Herbarios: ZSS

Nombre común: D esconocido.

Registro departamental: PA.

Regiones Ecológicas: MA; 3500-4000 m.

SINAN PE: Sin registro.

Hemarios peruanos: Ninguno.

Observaciones: Este cactus arborescente se conoce solamente de una localidad en Pasco. Esta especie se halla en el comercio de plantas ornamentales.

\section{Browningia chlorocarpa (Kunth) W.T. Marshall}

\section{LC}

Publicación: Cact. Succ. J. (Los Angeles) 17:114. 1945.

Colección tipo: A. Humboldt \& A. Bonpland s.n.

Henbarios: $P$.

Nombre común: D esconocido.

Registro departamental: CA, LA, PI.

Regiones Ecológicas: DCT, MDE; 400-

$2100 \mathrm{~m}$.

SINAN PE: Sin registro.

Herbarios penuanos: USM (5).
Observaciones: Cactus arbustivo conocido de varias localidades en las vertientes occidentales del norte, así como al parecer en la cuenca del Utcubamba (Pino, 1998). Estas poblaciones se encuentran naturalmente fragmentadas. Poco se sabe de sus afinidades taxonómicas que requieren aclararse.

\section{Browningia columnaris F. Ritter}

\section{LC}

Publicación: Kakteen Sudamer. 4(1): 123. 1981.

Colección tipo: F. Ritter 1294

Hemarios: SG O, U, ZSS.

Nombre común: D esconocido.

Registro departamental: AY.

Regiones Ecológicas: MD E; 1500- 2500 $\mathrm{m}$.

SINANPE: Sin registro.

Herbarios peruanos: Ninguno.

Observaciones: Cactus columnar conocido de una localidad en la vertiente del Pacífico del Departamento de Ayacucho. Su estatus taxonómico requiere evaluación, pero para ello se necesita mayor exploración y colecciones botánicas.

\section{Browningia hertlingiana (Rauh) Buxb.}

LC

Publicación: Kakteen Sudamer. 4(1): 104. 1965.

Colección tipo: F. Ritter 149

Herbarios: U.

Nombre común: Sanque grande.

Registro departamental: AP, AY, HV.

Regiones Ecológicas: MDE, BS; 1900$3000 \mathrm{~m}$.

SINAN PE: Sin registro.

Henbarios peruanos: USM (2).

Observaciones: Este cactus arbóreo ha sido encontrado en bosques secos interandinos del centro del país.

\section{Browningia pilleifera (F. Ritter) Hutchison}

\section{VU, C1c}

Publicación: J. Cact. Succ. Soc. Amer. 40:23. 1968.

Colección tipo: F. Ritter 659

Henbarios: U.

Nombre común: D esconocido.

Registro departamental: AM, CA.

Regiones Ecológicas: MDE, BS; 500$1500 \mathrm{~m}$.

SINANPE: Sin registro.

Herbarios peruanos: USM (3).

Observaciones: Este cactus arborescente de hasta $4 \mathrm{~m}$ de alto se conoce dela cuenca del río Marañón. Su estatus taxonómico requiere estudiarse con más detalle. Plantas de esta especie se encuentran en cultivo en el Jardín Botánico Privado de San Marcos en Cajamarca. O stolaza (1997) indica que las subpoblaciones de esta especie están generalmente integradas por menos de 2500 individuos. 
18. Browningia viridis (Rauh \& Backeb.) Buxb.

\section{NT}

Publicación: Kakteen Sudamer. 4: 6. 1965.

Colección tipo: W. Rauh K69b

Herbarios: ZSS.

Nombre común: Sara sanki.

Registro departamental: AP, AR, AY.

Regiones Ecológicas: MDE, MA; 1500$3000 \mathrm{~m}$

SINAN PE: RPSC

Herbarios peruanos: Ninguno.

Observaciones: Cactus arbóreo, como candelabro, hasta $10 \mathrm{~m}$. Parece estar cercanamente relacionada a Browningia hertlingiana (Anderson, 2001). Aceptada provisionalmente por Hunt (1999). No se han registrado colecciones desde el año 1957 y es posible que sus poblaciones se encuentre amenazadas debido a la expansión agrícola.

\section{Calymnanthium substerile F. Ritter}

$$
\text { CR, A2c }
$$

Publicación: Kakteen Sukk. 2:25-28. 1962.

Colección tipo: F. Ritter 315

Herbarios: U.

Nombre común: D esconocido.

Registro departamental: AM, CA.

Regiones Ecológicas: MDE, BS; 500$1000 \mathrm{~m}$.

SINAN PE: Sin registro.

Herbarios penuanos: USM (3).

Observaciones: Este cactus arbustivo, que puede llegar a ser arbóreo, está distribuido en laderas rocosas, valles secos y matorrales del norte del país. Se conoce en cultivo en Jardín Botánico San Marcos (Cajamarca). Esta especie requiere de estudios taxonómicos y de campo.

\section{Cereus vargasianus Cárdenas}

\section{DD}

Publicación: Succulenta 1951: 34. 1951.

Colección tipo: C. Vargas C. 7759

Herbarios: LP.

Nombre común: D esconocido.

Registro departamental: $\mathrm{CU}, \mathrm{HU}$.

Regiones Ecológicas: MDE; 400-1500 m.

SINAN PE: Sin registro.

Herbarios peruanos: Ninguno.

Observaciones: Cactus arborescente de hasta $8 \mathrm{~m}$ alto. Esta especie es aceptada provisionalmente por Hunt (1999).

\section{Cleistocactus acanthurus (Vaupel) D.R. H unt}

$$
\text { EN, Bla }
$$

Publicación: Bradleya 5. 1987.

Colección tipo: A. Weberbauer 1699

Herbarios: B.

Nombre común: Desconocido.

Registro departamental: IC, LI.

Regiones Ecológicas: D ST, MDE; 0$2500 \mathrm{~m}$.

SINAN PE: Sin registro.

Hemarios peruanos: USM (14).

Observaciones: Cactus arbustivo y decumbente conocido de localidades dispersas en el centro de la vertiente occidental del país.
22. Cleistocactus acanthurus (Vaupel) D.R. H unt subsp. faustianus O stolaza1998

\section{EN, Bla}

Publicación: Cactaceae Consensus Initiatives, 6: 8. 1998.

Colección tipo:

Herbarios:

Nombre común: D esconocido.

Registro departamental: LI.

Regiones Ecológicas: D ST, MDE; 0$2500 \mathrm{~m}$.

SINANPE: Sin registro.

Herbarios peruanos: Ninguno.

Observaciones: Esta subespecie de hábito columnar-arbustivo está restringida a Lima, creciendo en valles secos y laderas rocosas.

\section{Cleistocactus acanthurus (Vaupel) D.R. H unt subsp. pullatus 0 stolaza}

\section{EN, Bla}

Publicación: Cactaceae Consensus Initiatives, 6: 8. 1998.

Colección tipo:

Herbarios:

Nombre común: Desconocido.

Registro departamental: LI.

Regiones Ecológicas: D ST, MDE; $0-$ $2500 \mathrm{~m}$.

SINANPE: Sin registro.

Herbarios peruanos: Ninguno.

Observaciones: Esta subespecie de hábito columnar-arbustivo, que es conocida solamente de la colección tipo, está restringida a Lima, creciendo en laderas rocosas.

\section{Cleistocactus chotaensis A. Weber}

Publicación: Clesitocactus 19. 1904.

Colección tipo: André 3597

Herbarios:

Nombre común: D esconocido.

Registro departamental: LL.

Regiones Ecológicas: BS; altitud desconocida.

SINAN PE: Sin registro.

Herbarios peruanos: Ninguno.

Observaciones: Esta especie de cactus arbustiva se halla restringida a laderas y valles secos de La Libertad. No ha sido posible evaluarla, ni asignarle una categoría.

\section{Cleistocactus clavispinus (Rauh \& Backeb.) Ostolaza}

\section{CR, Bla}

Publicación: Brit. Cact. Succ. J. 16(3): 133. 1998.

Colección tipo: D esconocido

Herbarios:

Nombre común: D esconocido.

Registro departamental: IC.

Regiones Ecológicas: MDE, MA; $1000-$ $1500 \mathrm{~m}$.

SINAN PE: Sin registro.

Herbarios peruanos: Ninguno. 
Observaciones: Esta especie de cactus arbustiva está restringida a laderas rocosas y valles secos de Ica. Pocos especímenes han sido registrados en el camino entre Nazca y Lucanas (3000 m), los que probablemente consitituyen una sola población. Fue categorizada por Ostolaza (1998b) como especie en peligro crítico, la cual se acepta.

\section{Cleistocactus fieldianus (Britton \& Rose) D.R. H unt subsp. fieldianus}

Publicación:

Colección tipo: J.F. Macbride \& W. Featherstone 2519

Herbarios:

Nombre común: D esconocido.

Registro departamental: AN.

Regiones Ecológicas: MDE, MA; altitud desconocida.

SINANPE: PNH

Herbarios peruanos: USM (4).

Observaciones: Este taxón columnar-arbustivo ha sido registrado solamente para las vertientes occidentales de Ancash. El ejemplar tipo fue recolectado en 1922. No ha sido posible evaluarlo, ni asignarle una categoría.

\section{Cleistocactus fieldianus subsp. samnensis (F. Ritter) Ostolaza}

\section{EN, B2b(iii)}

Publicación:

Colección tipo: F. Ritter 304

Herbarios: SG O, ZSS.

Nombre común: D esconocido.

Registro departamental: AN, CA, LL.

Regiones Ecológicas: MDE; 1000-2000 m.

SINANPE: Sin registro.

Henbarios peruanos: USM (3).

Observaciones: Cactus arbustivo, erecto o semipostrado, conocido del norte del pais. Localmente, este taxón está representado por pocos individuos.

\section{Cleistocactus fieldianus (Britton \& Rose) D. R. Hunt subsp. tessellatus 0 stolaza}

\section{NE}

Publicación: Brit. Cact. Succ. J. 21(2): 92. 2003.

Colección tipo: D esconocido Sin datos

Hembarios: SG O, ZSS.

Nombre común: D esconocido.

Registro departamental: LI.

Regiones Ecológicas: MA; 2500-3000 $\mathrm{m}$.

SINANPE: Sin registro.

Hemarios peruanos: Ninguno.

Observaciones: Cactus decumbente, conocido solamente del D epartamento de Lima.
29. Cleistocactus hystrix (Rauh \& Backeb.) O stolaza

$$
\text { CR, Bla }
$$

Publicación: Brit. Cact. Succ. J. 16(3): 129. 1998.

Colección tipo: W. Rauh K112

Herbarios:

Nombre común: Desconocido.

Registro departamental: IC.

Regiones Ecológicas: DST, MDE; $3000 \mathrm{~m}$. SINAN PE: Sin registro.

Herbarios peruanos: Ninguno.

Observaciones: Cactus postrado conocido aparentemente sólo de una localidad a los $3000 \mathrm{~m}$, en el camino entre Nazca y Lucanas. Este taxón es considerado un híbrido entre Cleistocactus y H aageocereus, aunque a la elevación conocida, una de las especies parentales (H aageocereus) no ha sido observada (O stolaza, 1998b). O stolaza (1998b) consideró a esta especie en peligro crítico.

\section{Cleistocactus morawetzianus Backeb.}

Publicación: Jahrb. D eutsch. KakteenGes. 77. 1935.

Colección tipo: W. Rauh 75

Herbarios: HEID.

Nombre común: D esconocido.

Registro departamental: AY, HV.

Regiones Ecológicas: MDE; 2000— 2500 m.

SINANPE: Sin registro.

Hemanios penuanos: HUSA (2), USM (4).

Observaciones: Cactus arbustivo conocido del centro-sur del país. No ha sido posible evaluarlo, ni asignarle una categoría.

\section{Cleistocactus pachycladus (Rauh \& Backeb.) Ostolaza \\ NE}

Publicación: Cactaceae Consensus Initiatives, 6: 8. 1998.

Colección tipo: F. Ritter 657

Herbarios: ZSS

Nombre común: D esconocido.

Registro departamental: IC, LI.

Regiones Ecológicas: MDE; 2000- 3000 m.

SINANPE: Sin registro.

Herbarios peruanos: Ninguno.

Observaciones: Cactus arbustivo. Los especímenes estudiados provienen del este de Chincha Alta (2600 m), en los alrededores de Huacho y cerca de Lima. Esta especie es aceptada por Hunt (1999) y Anderson (2001). Incluye a Borzicadus piscensis (O stolaza 2002).

32. Cleistocactus peculiaris (Rauh \& Backeb.) Ostolaza

$$
\text { EN, Bla }
$$

Publicación: Brit. Cact. Succ. J. 16(3): 129. 1998.

Colección tipo:

Herbarios:

Nombre común: D esconocido.

Registro departamental: AP, HV, IC, LI. Regiones Ecológicas: DST, MDE; 600$1400 \mathrm{~m}$.

SINANPE: Sin registro.

Herbarios peruanos: Ninguno. 
Observaciones: Cactus arbustivo postrado conocido de la vertiente del Pacífico y de las cuencas del Apurímac y Mantaro, en el centro del país. Esta especie se halla en el comercio de plantas ornamentales.

\section{Cleistocactus plagiostoma (Vaupel) H unt}

\section{DD}

Publicación:

Colección tipo: A. Weberbauer 3906

Hembarios: $B$.

Nombre común: D esconocido.

Registro departamental: CA, LI.

Regiones Ecológicas: MDE, MA; 2000-

$2200 \mathrm{~m}$.

SINANPE: Sin registro.

Herbarios peruanos: Ninguno.

Observaciones: Cactus arbustivo, conocido originalmente de la cuenca del Marañón. A parentemente no ha vuelto a ser recolectada desde 1960.

\section{Cleistocactus pungens $\mathrm{F}$. Ritter}

\section{VU, Bla}

Publicación: Taxon 13(3): 115. 1964.

Colección tipo: F. Ritter 664

Hemarios: U, SG O, ZSS.

Nombre común: Desconocido.

Registro departamental: AP, AY.

Regiones Ecológicas: MA; 1500-2000 m.

SINANPE: SNA

Herbarios peruanos: Ninguno.

Observaciones: Cactus descrito de una plantya recolectada en la cuenca del Pampas. No se han registrado colecciones desde el año 1957 y es posible que sus poblaciones se encuentren amenazadas.

\section{Cleistocactus sextonianus (Backeb.) D.R. H unt}

\section{LC}

Publicación: Bradleya 9: 86. 1991.

Colección tipo: C. Backeberg s.n.

Herbarios: U, SG O, ZSS.

Nombre común: Desconocido.

Registro departamental: AR, AY, IC.

Regiones Ecológicas: DST, MDE; $0-$ $1500 \mathrm{~m}$.

SINANPE: Sin registro.

Herbarios penuanos: HUSA (1), USM (3).

Observaciones: Cactus postrado conocido de varias localidades en el centro y sur occidente del país.

\section{Cleistocactus tenuiserpens Rauh \& Backeb.}

\section{DD}

Publicación: Sitzungsber. Heidelberger Akad. Wiss., Math.-Naturwiss. Kl. 323. 1958.

Colección tipo: W. Rauh K 76

Herbarios: ZSS.

Nombre común: Desconocido.

Registro departamental: AM, CA, LA, PI. Regiones Ecológicas: MDE, BS; 500$1000 \mathrm{~m}$.

SINANPE: Sin registro.

Herbarios peruanos: HUT (1), USM (1).

Observaciones: Cactus arbustivo conocido del valle del Marañón, muy poco estudiado.
37. Cleistocactus X crassiserpens Rauh \& Backeb.

NE

Publicación: Sitzungsber. Heidelberger Akad. Wiss., Math.-Naturwiss. Kl. 321. 1958.

Colección tipo: W. Rauh 126

Herbarios: HEID.

Nombre común: D esconocido.

Registro departamental: PI.

Regiones Ecológicas: MDE; 1500- 2000

$\mathrm{m}$.

SINAN PE: Sin registro.

Herbarios peruanos: Ninguno.

Observaciones: Cactus arbustivo, que representa un híbrido natural entre Cleistocactus iosagonus y C. serpens.

\section{Cleistocactus xylorhizus (F. Ritter) O stolaza}

$$
\text { EN, B2a; D }
$$

Publicación: Brit. Cact. Succ. J. 14(4): 170 1996.

Colección tipo: D esconocido

Herbarios: Sin datos.

Nombre común: Desconocido.

Registro departamental: LI.

Regiones Ecológicas: DST, MDE; 0$1500 \mathrm{~m}$.

SINAN PE: Sin registro.

Herbarios peruanos: Ninguno.

Observaciones: Especie conocida aparentemente sólo de los valles del Rímac y Lurín.

\section{Corryocactus acervatus F. Ritter}

Publicación: Kakteen Sudamer. 4: 1287. 1981.

Colección tipo: F. Ritter 558

Hemanios: U.

Nombre común: Desconocido.

Registro departamental: AR.

Regiones Ecológicas: MA; 3000-3500 m.

SINAN PE: Sin registro.

Herbarios peruanos: USM (1).

Observaciones: Aceptada provisionalmente por Hunt (1999), pero considerada sinónimo de Corryocactus aureus por Anderson (2001). No ha sido posible evaluarla, ni asignarle una categoría.

\section{Corryocactus apiciflorus (Vaupel) Hutchison}

Publicación: Sukkulentenkunde 7-8: 9. 1963.

Colección tipo: A. Weberbauer 3743

Hemanios: B.

Nombre común: D esconocido.

Registro departamental: AN.

Regiones Ecológicas: MA; 2500-3000 m.

SINANPE: Sin registro.

Herbarios peruanos: USM (3).

Observaciones: Cactus arbustivo de hasta $50 \mathrm{~cm}$ de alto, con ramas ascendentes. Esta especie fue descrita de una planta recolectada a inicios del siglo XX. No ha sido posible evaluarlo, ni asignarle una categoría. 


\section{Corryocactus aureus (Meyen) H utchison}

Publicación: Sukkulentenkunde 7-8: 9. 1963. Colección tipo: J.N. Rose 18801

Herbarios:

Nombre común: D esconocido.

Registro departamental: AR.

Regiones Ecológicas: MDE; 2000 - 2500 m.

SINAN PE: Sin registro.

Herbarios penuanos: HUSA (9).

Observaciones: De acuerdo a Anderson (2001) debería incluir Corryocactus acervatus con lo que no concordamos. Corryocactus aureus forma colonias con tallos erectos cortos conectados por raíces subterráneas; mientras que $\mathrm{C}$. acervatus posee tallos postrados alargados. No ha sido posible evaluarla, ni asignarle una categoría.

\section{Corryocactus ayacuchoensis Rauh \& Backeb.}

Publicación: Stizungsber. Heidelberger Akad. Wiss., Math.-Naturwiss. Kl. 246. 1958.

Colección tipo: W. Rauh 73

Herbarios:

Nombre común: D esconocido.

Registro departamental: AY.

Regiones Ecológicas: MA; 2500-3000 m.

SINANPE: Sin registro.

Herbarios penuanos: HUSA (2), USM (2).

Observaciones: Aceptada provisionalmente por Hunt (1999), pero considerada como sinónimo de Corryocactus brevistylus por Anderson (2001). No ha sido posible evaluarla, ni asignarle una categoría.

\section{Corryocactus brachycladus F. Ritter}

Publicación: Kakteen Sudamer. 4: 1289. 1981.

Colección tipo: F. Ritter 657

Herbarios:

Nombre común: D esconocido.

Registro departamental: AN.

Regiones Ecológicas: MA; 3500-4000 m.

SINAN PE: Sin registro.

Herbarios peruanos: Ninguno.

Observaciones: Aceptada provisionalmente por Hunt (1999), pero considerada sinónimo de Corryocactus squarrosus por Anderson (2001). No ha sido posible evaluarla, ni asignarle una categoría.

\section{Corryocactus brachypetalus (Vaupel) Britton \& Rose}

Publicación: Cact. 2: 67-68, f. 100, 102-103. 1920.

Colección tipo: A. Weberbauer 1549

Herbarios:

Nombre común: D esconocido.

Registro departamental: AR.

Regiones Ecológicas: D ST; 0-1000 m.

SINAN PE: Sin registro.

Herbarios peruanos: USM (6).

Observaciones: Cactus arbustivo de tallos erectos, hasta $4 \mathrm{~m}$ de alto. No ha sido posible evaluarlo, ni asignarle una categoría.
45. Corryocactus brevispinus Rauh \& Backeb.

Publicación: Descr. Cact. Nov. 12. 1957. Colección tipo: Anónimo s.n.

Herbarios:

Nombre común: D esconocido.

Registro departamental: AR.

Regiones Ecológicas: MA; 2500-3000 m.

SINAN PE: Sin registro.

Herbarios peruanos: Ninguno.

Observaciones: Cactus arbustivo erecto. Esta especie fue aceptada provisionalmente por Hunt (1999), pero considerada sinónimo de Corryocactus brevistylus por Anderson (2001). No ha sido posible evaluarlo, ni asignarle una categoría.

\section{Corryocactus brevistylus (K. Schum) Britton \& Rose subsp. puquiensis (Rauh \& Backeb.) Ostolaza}

\section{NE}

Publicación: Cactaceae Consensus Initiatives, 6: 8. 1998.

Colección tipo: W. Rauh K48

Herbarios:

Nombre común: Sanqui.

Registro departamental: AR, AY.

Regiones Ecológicas: MA; 2500-3000 m.

SINANPE: RNPG

Herbarios penuanos: HUSA (1).

Observaciones: Cactus arbustivo que es conocido de unas pocas poblaciones en el sur del país. Este taxón fue listado por Brako \& Zarucchi (1993) en la sinonimia de Corryocactus puquiensis; sin embargo, Hunt (1999) y Anderson (2001) aceptan su estatus subespecífico.

\section{Corryocactus chachapoyensis Ochoa \& Backeb.}

Publicación: Die Cact. 2:859. 1959.

Colección tipo: C. O choa s.n.

Herbarios:

Nombre común: D esconocido.

Registro departamental: AM.

Regiones Ecológicas: MDE; 2000 - 2500 m.

SINAN PE: Sin registro.

Herbarios peruanos: USM (1).

Observaciones: Cactus trepador, con problemas nomenclaturales. No ha sido posible evaluarlo, ni asignarle una categoría.

\section{Corryocactus chavinilloensis F. Ritter}

Publicación: Kakteen Sudamer. 4: 1290. 1981.

Colección tipo: F. Ritter 689

Hemarios: U.

Nombre común: D esconocido.

Registro departamental: $\mathrm{HU}$.

Regiones Ecológicas: MA; 3000-3500 m.

SINANPE: Sin registro.

Herbarios peruanos: Ninguno. 
Observaciones: Cactus trepador. Aceptada provisionalmente por Hunt (1999), pero incluida como sinónimo de C orryocadus squarrosus por Anderson (2001). No ha sido posible evaluarlo, ni asignarle una categoría.

\section{Corryocactus cuajonesensis F. Ritter}

Publicación: Kakteen Sudamer. 4: 1287. 1981. Colección tipo: F. Ritter 638

Herbarios:

Nombre común: D esconocido.

Registro departamental: MO.

Regiones Ecológicas: MA; 3000-3500 m.

SINANPE: Sin registro.

Hemarios peruanos: Ninguno.

Observaciones: Cactus conocido del sur del país. No ha sido posible evaluarlo, ni asignarle una categoría.

\section{Corryocactus erectus (Backeb.) F. Ritter}

Publicación: Kakteen Sudamer. 4: 1281. 1981.

Colección tipo: W. Rauh 59

Herbarios:

Nombre común: D esconocido.

Registro departamental: CU.

Regiones Ecológicas: MA; 3000-4000 m.

SINAN PE: SHMP

Herbarios peruanos: Ninguno.

Observaciones: Cactus arbustivo, semipostrado a erecto, hasta 1 $\mathrm{m}$ de alto. No ha sido posible evaluarlo, ni asignarle una categoría.

\section{Corryocactus gracilis F. Ritter}

Publicación: Kakteen Sudamer. 4: 1282. 1981.

Colección tipo: F. Ritter 1299

Herbarios:

Nombre común: D esconocido.

Registro departamental: AP, AY.

Regiones Ecológicas: MDE; 2000— 2500 m.

SINAN PE: Sin registro.

Hemarios peruanos: Ninguno.

Observaciones: Cactus trepador. Aceptada provisionalmente por Hunt (1999), pero colocado como sinónimo deC orryocactus squarrosus por Anderson (2001). No ha sido posible evaluarlo, ni asignarle una categoría.

\section{Corryocactus heteracanthus Backeb.}

Publicación: Stizungsber. Heidelberger Akad. Wiss., Math.-Naturwiss. Kl. 246. 1958.

Colección tipo: W. Rauh 76

Herbarios:

Nombre común: D esconocido.

Registro departamental: AY.

Regiones Ecológicas: MDE; 2000-2500

$\mathrm{m}$.

SINANPE: Sin registro.

Herbarios peruanos: Ninguno.
Observaciones: Cactus trepador. Esta especie, con problemas taxonómicos, fue aceptada provisionalmente por Hunt (1999), pero colocada como sinónimo de Corryocactus brevistylus por Anderson (2001). No ha sido posible evaluarlo, ni asignarle una categoría.

\section{Corryocactus huincoensis F. Ritter}

Publicación: Kakteen Sudamer. 4: 1288. 1981. Colección tipo: F. Ritter 1070

Herbarios:

Nombre común: Desconocido.

Registro departamental: LI.

Regiones Ecológicas: MDE; 1500- $2000 \mathrm{~m}$.

SINAN PE: Sin registro.

Hembarios peruanos: Ninguno.

Observaciones: Cactus arbustivo, semierecto a péndulo, hasta 1.5 $\mathrm{m}$ de alto. No ha sido posible evaluarlo, ni asignarle una categoría.

\section{Corryocactus matucanensis F. Ritter}

Publicación: Kakteen Sudamer. 4: 1287. 1981. Colección tipo: F. Ritter 629

Herbarios:

Nombre común: Desconocido.

Registro departamental: LI.

Regiones Ecológicas: MDE; 2000 - 2500 m.

SINAN PE: Sin registro.

Hembarios peruanos: Ninguno.

Observaciones: Cactus trepador. Fue considerada sinónimo de Corryocactus huinowensis por Anderson (2001). No ha sido posible evaluarlo, ni asignarle una categoría.

\section{Corryocactus megarhizus F. Ritter}

Publicación: Kakteen Sudamer. 4: 1286.

1981.

Colección tipo: F. Ritter 559

Herbarios:

Nombre común: D esconocido.

Registro departamental: AY.

Regiones Ecológicas: MDE; 2000- 2500

m.

SINANPE: Sin registro.

Herbarios peruanos: Ninguno.

Observaciones: Cactus postrado. Esta especie fue aceptada por Hunt (1999), pero incluida como sinónimo de Corryocactus squarrosus por Anderson (2001). No ha sido posible evaluarlo, ni asignarle una categoría.

\section{Corryocactus melaleucus F. Ritter}

Publicación: Kakteen Sudamer. 4: 1289.

1981.

Colección tipo: F. Ritter 687

Herbarios: U.

Nombre común: D esconocido.

Registro departamental: LI.

Regiones Ecológicas: MA; 2500-3000

$\mathrm{m}$.

SINAN PE: Sin registro.

Herbarios penuanos: USM (1). 
Observaciones: Cactus trepador o postrado. Esta especie fue aceptada provisionalmente por Hunt (1999), pero colocada como sinónimo de Corryocactus squarrosus por Anderson (2001). O stolaza (2005) la categorizó como En Peligro Crítico; pero aquí no ha sido posible evaluarlo, ni asignarle una categoría.

\section{Corryocactus odoratus F. Ritter}

Publicación: Kakteen Sudamer. 4: 1285. 1981.

Colección tipo: F. Ritter 1301

Herbarios: U.

Nombre común: D esconocido.

Registro departamental: HV.

Regiones Ecológicas: MA; 3000-3500 $\mathrm{m}$.

SINAN PE: Sin registro.

Herbarios peruanos: Ninguno.

Observaciones: Cactus arbustivo postrado. Esta especie fue aceptada provisionalmente por Hunt (1999), pero colocada como sinónimo de Corryocactus squarrosus por Anderson (2001). No ha sido posible evaluarlo, ni asignarle una categoría.

\section{Corryocactus pilispinus F. Ritter}

Publicación: Kakteen Sudamer. 4: 1291. 1981.

Colección tipo: F. Ritter 1071

Herbarios: U.

Nombre común: D esconocido.

Registro departamental: LL.

Regiones Ecológicas: MA; 2500-3000 m.

SINAN PE: Sin registro.

Herbarios peruanos: Ninguno.

Observaciones: Cactus arbustivo postrado. Esta especie fue aceptada provisionalmente por Hunt (1999), pero colocada como sinónimo de Corryocactus squarrosus por Anderson (2001). No ha sido posible evaluarlo, ni asignarle una categoría.

\section{Corryocactus prostratus F. Ritter}

Publicación: Kakteen Sudamer. 4: 1283. 1981.

Colección tipo: F. Ritter 180

Herbarios: U.

Nombre común: D esconocido.

Registro departamental: AR.

Regiones Ecológicas: MDE, MA; 1500 $3000 \mathrm{~m}$.

SINAN PE: Sin registro.

Herbarios peruanos: USM (1).

Observaciones: Esta especie fue aceptada provisionalmente por Hunt (1999), pero colocada como sinónimo de Corryocactus aureus por Anderson (2001). No ha sido posible evaluarlo, ni asignarle una categoría.

\section{Corryocactus pyroporphyranthus F. Ritter}

Publicación: Kakteen Sudamer. 4:1284. 1981.

Colección tipo: F. Ritter 1481

Herbarios: U.

Nombre común: D esconocido.

Registro departamental: AY.

Regiones Ecológicas: MA; 3000-3500 m.

SINANPE: Sin registro.

Herbarios peruanos: Ninguno.

Observaciones: Cactus semipostrado. Esta especie fue aceptada provisionalmente por Hunt (1999), pero considerada como sinónimo de Corryocactus erectus por Anderson (2001). No ha sido posible evaluarlo, ni asignarle una categoría.

\section{Corryocactus quadrangularis (Rauh \& Backeb.) F. Ritter}

Publicación: 1958.

Colección tipo: W. Rauh 120

Herbarios:

Nombre común: D esconocido.

Registro departamental: AY.

Regiones Ecológicas: MA; 3000 - 3500 m.

SINAN PE: Sin registro.

Herbarios peruanos: USM (2).

Observaciones: Cactus arbustivo postrado, a veces péndulo. No ha sido posible evaluarlo, ni asignarle una categoría.

\section{Corryocactus quivillanus F. Ritter}

Publicación: Kakteen Sudamer. 4:1290. 1981.

Colección tipo: F. Ritter 688

Herbarios:

Nombre común: D esconocido.

Registro departamental: HU.

Regiones Ecológicas: MA; 2500-3000 m.

SINAN PE: Sin registro.

Herbarios peruanos: Ninguno.

Observaciones: Esta especie fue aceptada por Hunt (1999), pero incluida como sinónimo de Corryocadus squarrosus por Anderson (2001). No ha sido posible evaluarla, ni asignarle una categoría.

\section{Corryocactus serpens F. Ritter}

Publicación: Kakteen Sudamer. 4:1285. 1981.

Colección tipo: F. Ritter 1302

Herbarios:

Nombre común: D esconocido.

Registro departamental: HV.

Regiones Ecológicas: MA; 2500-3000 m.

SINAN PE: Sin registro.

Herbarios peruanos: Ninguno.

Observaciones: Esta especie fue aceptada por Hunt (1999), pero incluida como sinónimo de Corryocactus erectus por Anderson (2001). No ha sido posible evaluarla, ni asignarle una categoría. 
64. Corryocactus solitarius F. Ritter

Publicación: Kakteen Sudamer. 4:1289. 1981.

Colección tipo: F. Ritter 634

Herbarios: U.

Nombre común: D esconocido.

Registro departamental: LL.

Regiones Ecológicas: MA; 3000-3500

m.

SINANPE: Sin registro.

Herbarios peruanos: Ninguno.

Observaciones: Esta especie fue aceptada por Hunt (1999), pero incluida como sinónimo de Corryocactus apiciflorus por Anderson (2001). No ha sido posible evaluarlo, ni asignarle una categoría.

\section{Corryocactus tenuiculus (Rauh \& Backeb.) Hutchison}

Publicación: Sukkulentenkunde 7-8: 9. 1963.

Colección tipo: W. Rauh 54

Herbarios:

Nombre común: D esconocido.

Registro departamental: AN.

Regiones Ecológicas: MA, PSH; 3500$4500 \mathrm{~m}$.

SINANPE: Sin registro.

Herbarios peruanos: Ninguno.

Observaciones: Esta especie fue aceptada por Hunt (1999), pero incluida como sinónimo de Corryocactus squarrosus por Anderson (2001). No ha sido posible evaluarlo, ni asignarle una categoría.

\section{Cumulopuntia galerasensis F. Ritter}

Publicación: Kakteen Sudamer. 4: 1249. 1981.

Colección tipo: F. Ritter 1045

Herbarios: U.

Nombre común: D esconocido.

Registro departamental: AY.

Regiones Ecológicas: MA; 3000-3500

$\mathrm{m}$

SINANPE: RNPG

Herbarios peruanos: HUSA (1).

Observaciones: Cactus que forma cojines densos. No ha sido posible evaluarlo, ni asignarle una categoría.

\section{Cumulopuntia tumida F. Ritter}

Publicación: Kakteen Sudamer. 4: 1254. 1981.

Colección tipo: F. Ritter 1324

Herbarios: U.

Nombre común: D esconocido.

Registro departamental: AR.

Regiones Ecológicas: D ST; 0-500 m.

SINANPE: Sin registro.

Herbarios peruanos: Ninguno.

Observaciones: Cactus que forma cojines densos. No ha sido posible evaluarlo, ni asignarle una categoría.
68. Echinopsis cephalomacrostibas (Werderm. \&

Backeb.) Friedrich \& G.D. Rowley

Publicación: Int. O rgan. Succ. Pl. Study Bull. 3(3): 94. 1974.

Colección tipo: Desconocido Sin datos

Herbarios:

Nombre común: D esconocido.

Registro departamental: AR.

Regiones Ecológicas: D ST; $500-800 \mathrm{~m}$.

SINANPE: Sin registro.

Herbarios peruanos: Ninguno.

Observaciones: Cactus arbustivo de ramas erectas, hasta $2 \mathrm{~m}$ de alto. No ha sido posible evaluarlo, ni asignarle una categoría.

\section{Echinopsis chalaensis (Rauh \& Backeb.) Friedrich \& G.D. Rowley}

Publicación: Int. Organ. Succ. Pl. Study Bull. 3(3): 94. 1974.

Colección tipo: W. Rauh 128

Herbarios:

Nombre común: D esconocido.

Registro departamental: AR.

Regiones Ecológicas: D ST; 0-500 m.

SINAN PE: Sin registro.

Herbarios peruanos: Ninguno.

Observaciones: Cactus arbustivo de ramas erectas, hasta $4 \mathrm{~m}$ de alto. No ha sido posible evaluarlo, ni asignarle una categoría.

\section{E chinopsis cuzcoensis (Britton \& Rose) Friedrich \& G.D. Rowley}

Publicación: Int. O rgan. Succ. Pl. Study Bull. 3(3): 95. 1974.

Colección tipo: C. Backeberg s.n.

Herbarios:

Nombre común: Avacollay.

Registro departamental: CU.

Regiones Ecológicas: MA; 3100-3600

$\mathrm{m}$.

SINAN PE: Sin registro.

Herbarios peruanos: Ninguno.

Observaciones: Cactus arbóreo de ramas erectas, hasta $6 \mathrm{~m}$ de alto. No ha sido posible evaluarlo, ni asignarle una categoría.

\section{Echinopsis knuthiana (Backeb.) Friedrich \& G.D. Rowley}

Publicación: Int. O rgan. Succ. Pl. Study Bull. 3(3): 96. 1974.

Colección tipo: J.N. Rose 19022

Herbarios:

Nombre común: D esconocido.

Registro departamental: AY.

Regiones Ecológicas: MA; 2500-3000 m.

SINANPE: Sin registro.

Hembarios peruanos: Ninguno.

Observaciones: Cactus arbustivo, de ramas cerca de la base, hasta $3 \mathrm{~m}$ de alto. No ha sido posible evaluarlo, ni asignarle una categoría. 
72. Echinopsis pampana (Britton \& Rose) D.R. Hunt

Publicación: Bradleya 9:88. 1991.

Colección tipo: J.N. Rose 18966

Herbarios:

Nombre común: D esconocido.

Registro departamental: AR.

Regiones Ecológicas: PD; 3500-4000 m.

SINAN PE: Sin registro.

Herbarios peruanos: Ninguno.

Observaciones: Cactus globoso descrito de una planta recolectada en el sur del país. No ha sido posible evaluarlo, ni asignarle una categonía.

\section{Echinopsis penuviana (Britton \& Rose) H. Friedrich} \& G. D. Rowley subsp. penuviana

NE

Publicación:

Colección tipo: J.N. Rose \& G. Rose 18658

Herbarios: U, SGO, ZSS.

Nombre común: D esconocido.

Registro departamental: AN, CA, JU, LI, MO, TA.

Regiones Ecológicas: MA; 3000-3500 m.

SINANPE: Sin registro.

Herbarios peruanos: USM (8).

Observaciones: Cactus arbustivo de taxonomía dudosa. Hunt (1999) aceptó este taxón, pero incluyó E chinopsis tacnaensis y E. torataensis como sinónimos de E . peruviana, con lo cual no se trataría de una especie endémica. Sin embargo, O stolaza (2005) acepta E chinopsis peruviana subsp. peruviana en un sentido más restringido, excluyendo esas especies. Podría estar representada en la flora de Bolivia o Chile.

\section{Echinopsis penuviana (Britton \& Rose) H. Friedrich \& G. D. Rowley subsp. puquiensis (Rauh \& Backeb.) Ostolaza 1998}

\section{NE}

Publicación: Cactaceae Consensus Initiatives, 6: 8. 1998

Colección tipo: W. Rauh K119

Herbarios: ZSS

Nombre común: D esconocido.

Registro departamental: AY.

Regiones Ecológicas: MA; 3000-3500 m.

SINAN PE: Sin registro.

Herbarios peruanos: USM (5).

Observaciones: Cactus arbustivo conocido aparentemente de unas cinco colecciones. Su taxonomía es dudosa.

\section{Echinopsis santaensis (Rauh \& Backeb.) Friedrich \& G.D. Rowley}

Publicación: Int. Organ. Succ. Pl. Study Bull. 3(3): 97. 1974

Colección tipo: W. Rauh 58

Herbarios:

Nombre común: Desconocido.

Registro departamental: AN.

Regiones Ecológicas: MDE; 2000- 2500 m.

SINANPE: Sin registro.

Herbarios peruanos: Ninguno.
Observaciones: Cactus arbustivo. No ha sido posible evaluarlo, ni asignarle una categoría.

\section{Echinopsis schoenii (Rauh \& Backeb.) Friedrich \& G.D. Rowley}

Publicación: Int. O rgan. Succ. Pl. Study Bull. 3(3): 97. 1974.

Colección tipo: W. Rauh 185

Herbarios:

Nombre común: D esconocido.

Registro departamental: AR.

Regiones Ecológicas: MA, PSH; 3500$4000 \mathrm{~m}$.

SINANPE: Sin registro.

Herbarios peruanos: Ninguno.

Observaciones: Cactus arbustivo. No ha sido posible evaluarlo, ni asignarle una categoría.

\section{Echinopsis tarmaensis (Rauh \& Backeb.) Friedrich \& G.D. Rowley}

Publicación: Int. O rgan. Succ. Pl. Study Bull. 3(3): 98. 1974.

Colección tipo: W. Rauh 8

Herbarios:

Nombre común: D esconocido.

Registro departamental: JU.

Regiones Ecológicas: MA; 2500-3500 m.

SINANPE: Sin registro.

Henbarios peruanos: USM (2).

Observaciones: Cactus arbustivo. No ha sido posible evaluarlo, ni asignarle una categoría.

\section{Echinopsis tegeleriana (Backeb.) D.R. Hunt}

Publicación: Bradleya 5:92. 1987.

Colección tipo: Backeberg s.n.

Herbarios:

Nombre común: D esconocido.

Registro departamental: AY.

Regiones Ecológicas: MA, PSH; 3000-

$4000 \mathrm{~m}$.

SINANPE: Sin registro.

Herbarios peruanos: Ninguno.

Observaciones: Cactus arbustivo. No ha sido posible evaluarlo, ni asignarle una categoría.

\section{Echinopsis tulhuayacensis (0choa ex Backeb.) Friedrich \& G.D. Rowley}

Publicación: Int. Organ. Succ. Pl. Study Bull. 3(3): 99. 1974.

Colección tipo: C. O choa s.n.

Herbarios:

Nombre común: D esconocido.

Registro departamental: HU.

Regiones Ecológicas: MA; altitud desconocida.

SINAN PE: Sin registro.

Herbarios peruanos: Ninguno. 
Observaciones: Cactus arbustivo. No ha sido posible evaluarlo, ni asignarle una categoría.

\section{E piphyllum floribundum Kimnach}

Publicación: Cact. Succ. J. (Los Angeles) 62: 85. 1990.

Colección tipo: Mathias s.n.

Herbarios:

Nombre común: D esconocido.

Registro departamental: LO.

Regiones Ecológicas: BHA; 0-500 m.

SINANPE: Sin registro.

Hemarios penuanos: USM (11).

Observaciones: Cactus epífito, de ramas aplanadas. No ha sido posible evaluarlo, ni asignarle una categoría.

\section{E niosyce islayensis (Foerst.) Katt.}

\section{LC}

Publicación: Eriosyce (Cactac.) gen. revis. \& ampl. 1: 117. 1994.

Colección tipo: W. Rauh K78

Herbarios: SG O, ZSS.

Nombre común: D esconocido.

Registro departamental: AR, IC, LI, MO, TA.

Regiones Ecológicas: D ST, MDE; 0$1500 \mathrm{~m}$.

SINANPE: Sin registro.

Herbarios penuanos: USM (9).

Observaciones: Cactus globoso conocido de varias localidades del centro y sur del país; probablemente esta especie también esté representada en la flora chilena.

\section{E spostoa baumannii Knize}

Publicación: Biota 7(57): 263. 1968.

Colección tipo: Knize 300

Herbarios:

Nombre común: D esconocido.

Registro departamental: AM.

Regiones Ecológicas: MD E; 2000- 2500

$\mathrm{m}$

SINAN PE: Sin registro.

Herbarios peruanos: Ninguno.

Observaciones: Cactus arbustivo. No ha sido posible evaluarlo, ni asignarle una categoría.

\section{E spostoa blossfeldiorum (Werderm.) Buxb.}

Publicación: O esterr. Bot. Z. 106: 155. 1959.

Colección tipo: F. Ritter 306

Herbarios:

Nombre común: D esconocido.

Registro departamental: CA, PI.

Regiones Ecológicas: MDE, BS; 1500$2500 \mathrm{~m}$

SINAN PE: Sin registro.

Herbarios penuanos: USM (5).

Observaciones: Cactus arbustivo. No ha sido posible evaluarlo, ni asignarle una categoría.

\section{Espostoa calva F. Ritter}

Publicación: Kakteen Sudamer. 4: 1432. 1981.

Colección tipo: F. Ritter 1314

Herbarios:

Nombre común: D esconocido.

Registro departamental: AM.

Regiones Ecológicas: MDE, BS; $1500-$ $2500 \mathrm{~m}$.

SINAN PE: Sin registro.

Herbarios peruanos: USM (1).

Observaciones: Cactus arbustivo. No ha sido posible evaluarlo, ni asignarle una categoría.

\section{Espostoa huanucoensis Johnson ex F. Ritter}

Publicación: Kakteen Sudamer. 4: 1435.

1981.

Colección tipo: F. Ritter 665

Herbarios:

Nombre común: D esconocido.

Registro departamental: $\mathrm{HU}$.

Regiones Ecológicas: MDE; 1500- 2000

m.

SINANPE: Sin registro.

Hembarios peruanos: Ninguno.

Observaciones: Cactus arbustivo. No ha sido posible evaluarlo, ni asignarle una categoría.

\section{E spostoa hylaea F. Ritter}

Publicación: Taxon 13(4):143. 1964.

Colección tipo: F. Ritter 668

Herbarios:

Nombre común: D esconocido.

Registro departamental: AM.

Regiones Ecológicas: BS; 0-500 m.

SINANPE: Sin registro.

Henbarios peruanos: Ninguno.

Observaciones: Cactus arbustivo. No ha sido posible evaluarlo, ni asignarle una categoría.

\section{E spostoa lanianuligera F. Ritter}

Publicación: Kakteen Sudamer. 4: 1443. 1981.

Colección tipo: F. Ritter 660

Herbarios: U.

Nombre común: D esconocido.

Registro departamental: CA.

Regiones Ecológicas: MDE; 2000- 2500

m.

SINAN PE: Sin registro.

Henbarios penuanos: USM (1).

Observaciones: Cactus arbustivo. No ha sido posible evaluarlo, ni asignarle una categoría. 
Publicación: Cacti 112. 1937.

Colección tipo: A. Weberbauer 2630

Herbarios: B.

Nombre común: D esconocido.

Registro departamental: LI.

Regiones Ecológicas: D ST, MDE; 500$1000 \mathrm{~m}$.

SINANPE: Sin registro.

Herbarios penuanos: USM (7).

Observaciones: Cactus arbustivo, conocido originalmente de la cuenca del Rímac. No ha sido posible evaluarlo, ni asignarle una categoría.

\section{E spostoa mirabilis F. Ritter}

Publicación: Taxon 13(4): 143. 1964.

Colección tipo: F. Ritter 670

Herbarios: U.

Nombre común: D esconocido.

Registro departamental: AM, CA.

Regiones Ecológicas: BS; 500-1000 m.

SINAN PE: Sin registro.

Herbarios peruanos: USM (1).

Observaciones: Esta especie fue recoletada en la cuenca del Marañón. No ha sido posible evaluarlo, ni asignarle una categoría.

\section{E spostoa nana F. Ritter}

Publicación: Taxon 13(4): 143. 1964.

Colección tipo: F. Ritter 166

Herbarios:

Nombre común: D esconocido.

Registro departamental: AN.

Regiones Ecológicas: MA; 1000-1500

$\mathrm{m}$.

SINANPE: Sin registro.

Hemarios peruanos: Ninguno.

Observaciones: Cactus arbustivo. No ha sido posible evaluarlo, ni asignarle una categoría.

\section{Espostoa ritteri Buining}

Publicación: Succulenta (Netherlands) 3: 25-27. 1960.

Colección tipo: F. Ritter 274

Herbarios:

Nombre común: D esconocido.

Registro departamental: CA.

Regiones Ecológicas: BS; 0-500 m.

SINAN PE: Sin registro.

Hembarios peruanos: Ninguno.

Observaciones: Cactus arbustivo. No ha sido posible evaluarlo, ni asignarle una categoría.

\section{E spostoa ruficeps F. Ritter}

Publicación: Kakteen Sudamer. 4: 1448. 1981.

Colección tipo: F. Ritter 573a

Herbarios:

Nombre común: D esconocido.

Registro departamental: AN.

Regiones Ecológicas: MDE; 2000— 2500 m.

SINANPE: Sin registro.

Herbarios penuanos: USM (1).

Observaciones: Cactus arbustivo. No ha sido posible evaluarlo, ni asignarle una categoría.

\section{E spostoa senilis (F. Ritter) N.P. Taylor}

Publicación: Cact. Succ. J. Gr. Brit. 40(2): 54. 1978.

Colección tipo: F. Ritter 569

Herbarios:

Nombre común: Desconocido.

Registro departamental: AN, LL.

Regiones Ecológicas: MDE; 2000- 2500

m.

SINANPE: Sin registro.

Herbarios peruanos: Ninguno.

Observaciones: Cactus arbustivo. No ha sido posible evaluarlo, ni asignarle una categoría.

\section{E spostoa superba F. Ritter}

Publicación: Kakteen Sukk. 6: 85-86. 1960.

Colección tipo: F. Ritter 572

Hemarios: U.

Nombre común: D esconocido.

Registro departamental: CA.

Regiones Ecológicas: MDE, BS; 560$800 \mathrm{~m}$.

SINAN PE: Sin registro.

Herbarios penuanos: HUT (1), USM (1).

Observaciones: Cactus arbustivo conocido de las cuencas del Chamaya y Marañón. No ha sido posible evaluarlo, ni asignarle una categoría.

\section{Espostoa utcubambensis G.J. Charles}

\section{NE}

Publicación: British Cactus \& Succ. J. 21(2): 69-74. 2003

Colección tipo: G. Charles et al. 573.01

Herbarios: Herb. Octavio Velarde.

Nombre común: D esconocido.

Registro departamental: AM.

Regiones Ecológicas: MDE, BS; 1350$1950 \mathrm{~m}$.

SINANPE: Sin registro.

H erbarios peruanos: Herb. O ctavio Velarde.

Observaciones: Cactus descrito de una planta recolectada en la cuenca del Utcubamba, en 2001. La colección original se halla en el Herbario del Jardín Botánico de la Universidad Agraria. 


\section{Eulychnia nitteri Cullman}

Publicación: Kakteen Sukk. 9: 121. 1958. Colección tipo: F. Ritter 276

Herbarios:

Nombre común: D esconocido.

Registro departamental: AR.

Regiones Ecológicas: DST; 0-500 m.

SINAN PE: Sin registro.

Herbarios peruanos: Ninguno.

Observaciones: Cactus arbustivo. No ha sido posible evaluarlo, ni asignarle una categoría.

\section{Haageocereus acranthus (Vaupel) Backeb. subsp. acranthus}

Publicación:

Colección tipo: A. Weberbauer 1679

Herbarios:

Nombre común: D esconocido.

Registro departamental: LI.

Regiones Ecológicas: D ST; altitud desconocida.

SINANPE: RNL

Hemarios peruanos: USM (2).

Observaciones: Cactus arbustivo. No ha sido posible evaluarlo, ni asignarle una categoría.

98. Haageoceneus acranthus (Vaupel) Backeb. subsp. deflexispinus (Rauh \& Backeb.) Ostolaza

Publicación: Brit. Cact. Succ. J. 21(2): 94. 2003.

Colección tipo:

Herbarios:

Nombre común: D esconocido.

Registro departamental: LI.

Regiones Ecológicas: MDE; altitud desconocida.

SINAN PE: Sin registro.

Herbarios peruanos: Ninguno.

Observaciones: Cactus arborescente conocido de la costa central del país. No ha sido posible evaluarlo, ni asignarle una categoría.

99. Haageocereus acranthus (Vaupel) Backeb. subsp. olowinskianus (Rauh \& Backeb.) Ostolaza

\section{EN, Blab(iii)}

Publicación: Cactaceae Consensus Initiatives, 6: 8. 1998.

Colección tipo:

Herbarios:

Nombre común: D esconocido.

Registro departamental: CA, LI.

Regiones Ecológicas: D ST; $200 \mathrm{~m}$.

SINAN PE: Sin registro.

Herbarios peruanos: USM (8).
Observaciones: Cactus arbustivo, observado sólo en la localidad tipo, las Lomas de Atocongo. Ostolaza (1995) reporta una sola población, de cerca de 500 individuos, en un área de $500 \mathrm{~m}^{2}$. La forma davispinus es similar a la forma olowinskianus, pero con espinas centrales más rígidas, como agujas (O stolaza 1995).

100. Haageocereus acranthus (Vaupel) Backeb. subsp. zonatus (Rauh \& Backeb.) Ostolaza

Publicación: Brit. Cact. Succ. J. 21(2): 94.

2003.

Colección tipo:

Herbarios:

Nombre común: D esconocido.

Registro departamental: AN, LI.

Regiones Ecológicas: MDE; altitud desconocida.

SINAN PE: Sin registro.

Herbarios peruanos: Ninguno.

Observaciones: Cactus arbustivo reconocible por un anillo de pelos en la zona de flores. No ha sido posible evaluarlo, ni asignarle una categoría.

\section{Haageocereus albispinus (Akers) Rauh \& Backeb.}

Publicación: Sitzungsber. Heidelberger Akad. Wiss., Math.-Naturwiss. Kl. 414. 1958.

Colección tipo: F. Ritter 1062

Herbarios:

Nombre común: D esconocido.

Registro departamental: LI.

Regiones Ecológicas: MDE; 1000—1500 m.

SINANPE: Sin registro.

Herbarios peruanos: Ninguno.

Observaciones: Cactus arbustivo, columnar, hasta $2 \mathrm{~m}$ de alto. No ha sido posible evaluarlo, ni asignarle una categoría.

\section{Haageocereus chalaensis F. Ritter}

Publicación: Kakteen Sudamer. 4: 1389. 1981. Colección tipo: F. Ritter 187

Herbarios:

Nombre común: D esconocido.

Registro departamental: AR.

Regiones Ecológicas: D ST; 0-500 m.

SINAN PE: Sin registro.

Herbarios penuanos: USM (1).

Observaciones: Cactus arbustivo. No ha sido posible evaluarlo, ni asignarle una categoría.

\section{Haageoceneus chryseus F. Ritter}

Publicación: Kakteen Sudamer. 4: 1390. 1981.

Colección tipo: F. Ritter 147a, 585

Herbarios:

Nombre común: D esconocido.

Registro departamental: AN.

Regiones Ecológicas: MDE; 1000- 1500

m.

SINANPE: Sin registro.

Herbarios peruanos: Ninguno. 
Observaciones: Cactus arbustivo, columnar, hasta $3 \mathrm{~m}$ de alto. No ha sido posible evaluarlo, ni asignarle una categoría.

\section{Haageocereus decumbens (Vaupel) Backeb.}

Publicación: Blatt. Kakteenf. 6: 2. 1934.

Colección tipo: A. Weberbauer 1550

Herbarios:

Nombre común: D esconocido.

Registro departamental: AR.

Regiones Ecológicas: D ST; 0-500 m.

SINANPE: Sin registro.

Henbarios peruanos: USM (10).

Observaciones: Cactus arbustivo decumbente. No ha sido posible evaluarlo, ni asignarle una categoría.

105. Haageocereus fulvus F. Ritter

Publicación: Kakteen Sudamer. 4: 1393.

1981.

Colección tipo: W. Rauh 51a

Herbarios:

Nombre común: D esconocido.

Registro departamental: AN.

Regiones Ecológicas: MDE; 1000- 2000

$\mathrm{m}$.

SINAN PE: Sin registro.

Henbarios peruanos: USM (1).

Observaciones: Cactus arbustivo, semierecto, hasta $2 \mathrm{~m}$ de alto. No ha sido posible evaluarlo, ni asignarle una categoría.

106. Haageocereus icensis Backeb. ex F. Ritter

Publicación: Kakteen Sudamer. 4: 1394. 1981.

Colección tipo: F. Ritter 146

Herbarios:

Nombre común: D esconocido.

Registro departamental: IC.

Regiones Ecológicas: DST; 0-500 m.

SINANPE: Sin registro.

Herbarios peruanos: Ninguno.

Observaciones: Cactus arbustivo, postrado o semierecto, hasta 2 $\mathrm{m}$ de alto. No ha sido posible evaluarlo, ni asignarle una categoría.

\section{Haageoceneus icosagonoides Rauh \& Backeb.}

Publicación: Sitzungsber. Heidelberger Akad. Wiss., Math.-Naturwiss. Kl. 402. 1958.

Colección tipo: W. Rauh 86

Herbarios:

Nombre común: D esconocido.

Registro departamental: LA.

Regiones Ecológicas: DCT, D ST; 0$1000 \mathrm{~m}$.

SINANPE: Sin registro.

Henbarios peruanos: USM (6).

Observaciones: Cactus arbustivo, columnar. No ha sido posible evaluarlo, ni asignarle una categoría.
108. Haageocereus lanugispinus $F$. Ritter

Publicación: Kakteen Sudamer. 4: 1395. 1981.

Colección tipo: F. Ritter 583

Herbarios:

Nombre común: D esconocido.

Registro departamental: AN, LI.

Regiones Ecológicas: MDE; 2000- 2500

m.

SINAN PE: Sin registro.

Herbarios peruanos: Ninguno.

Observaciones: Cactus arbustivo semipostrado. No ha sido posible evaluarlo, ni asignarle una categoría.

109. Haageocereus pacalaensis Backeb. subsp. pacalaensis

Publicación:

Colección tipo: F. Ritter 294

Herbarios:

Nombre común: D esconocido.

Registro departamental: AN, LL, LA.

Regiones Ecológicas: D ST; 150- 950 m.

SINAN PE: Sin registro.

Henbarios penuanos: HUT (2), USM (4).

Observaciones: Cactus arbustivo, ramificado desde la base. No ha sido posible evaluarlo, ni asignarle una categoría.

110. Haageocereus pacalaensis Backeb. subsp. repens (Rauh \& Backeb.) Ostolaza

$$
\text { CR, A3; B2a }
$$

Publicación: Brit. Cact. Succ. J. 18(3): 130. 2000.

Colección tipo:

Herbarios:

Nombre común: D esconocido.

Registro departamental: LL.

Regiones Ecológicas: DST, MDE; 0$1500 \mathrm{~m}$.

SINAN PE: Sin registro.

Herbarios peruanos: USM (3).

Observaciones: Cactus arbustivo postrado que sólo existe en una población, a $10 \mathrm{~km}$ al sur de la ciudad de Trujillo y restringida a 2 $\mathrm{km}^{2}$. D esde 2000 se ha registrado cerca de 400 individuos, número que ha ido decreciendo rápidamente por la expansión agrícola.

111. Haageoceneus platinospinus (Werderm. \& Backeb.) Backeb.

Publicación: Kaktus-ABC 209. 1935.

Colección tipo: F. Ritter 318

Herbarios:

Nombre común: D esconocido.

Registro departamental: AR, TA.

Regiones Ecológicas: MDE; 1000- 2000

m.

SINANPE: Sin registro.

Herbarios penuanos: HUSA (1), USM (2).

Observaciones: Cactus arbustivo, ramificado desde la base. No ha sido posible evaluarlo, ni asignarle una categoría. 
112. Haageocereus pluniflorus Rauh \& Backeb.

Publicación: Descr. Cact. Nov. 23. 1956. Colección tipo:

Herbarios:

Nombre común: D esconocido.

Registro departamental: AR.

Regiones Ecológicas: MDE; 1000—2000 m.

SINAN PE: Sin registro.

Herbarios peruanos: Ninguno.

Observaciones: Cactus arbustivo. Esta especie fue considerada en la sinonimia de $\mathrm{H}$ aageocereus platinospinus por Brako \& Zarucchi (1993). Reconocida como una especie diferente por Hunt (1999) y Anderson (2000). No ha sido posible evaluarlo, ni asignarle una categoría.

\section{Haageocereuspseudomelanostele(Werdem. \& Backeb.) Backeb. subsp. carminiflonus (Rauh\& Backeb.) Ostolaza}

Publicación: Cactaceae Consensus Initiatives, 6: 9. 1998.

Colección tipo:

Herbarios:

Nombre común: D esconocido.

Registro departamental: LI.

Regiones Ecológicas: MDE; altitud desconocida.

SINAN PE: Sin registro.

Herbarios peruanos: Ninguno.

Observaciones: Cactus arbustivo. No ha sido posible evaluarlo, ni asignarle una categoría.

\section{Haageocereus pseudomelanostele(Werderm.\& Backeb.) Backeb. subsp. pseudomelanostele}

\author{
Publicación: \\ Colección tipo: \\ Herbarios: \\ Nombre común: D esconocido. \\ Registro departamental: LI. \\ Regiones Ecológicas: D ST, MDE; 50- \\ $2000 \mathrm{~m}$. \\ SINANPE: Sin registro. \\ Herbarios penuanos: USM (2).
}

Observaciones: Cactus arbustivo. No ha sido posible evaluarlo, ni asignarle una categoría.

115. Haageocereus pseudomelanostele(Werderm.\& Backeb.) Backeb. subsp. acanthocladus(Rauh\& Backeb.) Ostolaza

Publicación: Brit. Cact. Succ. J. 21(2): 94. 2003.

Colección tipo:

Herbarios:

Nombre común: D esconocido.

Registro departamental: LI.

Regiones Ecológicas: MDE; 1400—1700 m.

SINANPE: Sin registro.

Herbarios peruanos: USM (2).
Observaciones: Cactus arbustivo. No ha sido posible evaluarlo, ni asignarle una categoría.

116. Haageocereus pseudomelanostele (Wenderm. \& Backeb.) Backeb. subsp. aureispinus (Rauh \& Backeb.) Ostolaza

Publicación: Cactaceae Consensus Initiatives, 6: 9. 1998.

Colección tipo:

Herbarios:

Nombre común: D esconocido.

Registro departamental: LI.

Regiones Ecológicas: D ST, MDE; 500$2000 \mathrm{~m}$.

SINAN PE: Sin registro.

Herbarios peruanos: USM (1).

Observaciones: Cactus arbustivo. No ha sido posible evaluarlo, ni asignarle una categoría.

117. Haageocereus pseudomelanostele (Wenderm. \& Backeb.) Backeb. subsp. setosus (Ackers) Backeb.

Publicación:

Colección tipo:

Herbarios:

Nombre común: D esconocido.

Registro departamental: LI.

Regiones Ecológicas: MDE; altitud desconocida.

SINANPE: Sin registro.

Herbarios peruanos: Ninguno.

Observaciones: Cactus arbustivo. No ha sido posible evaluarlo, ni asignarle una categoría.

118. Haageocereus pseudomelanostele (Werderm. \& Backeb.) Backeb. subsp. turbidus (Rauh \& Backeb.) O stolaza

Publicación: Cactaceae Consensus Initiatives, 6: 9. 1998.

Colección tipo:

Herbarios:

Nombre común: D esconocido.

Registro departamental: AY, IC.

Regiones Ecológicas: D ST, MDE; 500$2000 \mathrm{~m}$.

SINANPE: Sin registro.

Herbarios peruanos: USM (1).

Observaciones: Cactus arbustivo. No ha sido posible evaluarlo, ni asignarle una categoría. 
119. Haageocereus pseudoversicolor Rauh \& Backeb.

Publicación: Descr. Cact. Nov. 23. 1956.

Colección tipo:

Herbarios:

Nombre común: D esconocido.

Registro departamental: LA, LL.

Regiones Ecológicas: DCT; 200-500m

SINAN PE: Sin registro.

Herbarios peruanos: Ninguno.

Observaciones: Cactus arbustivo. Esta especie ha sido reconocida por Hunt (1999) y Anderson (2001). No ha sido posible evaluarlo, ni asignarle una categoría.

\section{Haageocereus subtilispinus F. Ritter}

Publicación: Kakteen Sudamer. 4: 1419.

1981.

Colección tipo: F. Ritter 582

Herbarios:

Nombre común: D esconocido.

Registro departamental: AR.

Regiones Ecológicas: D ST; 0- 500.

SINANPE: Sin registro.

Herbarios peruanos: Ninguno.

Observaciones: Cactus arbustivo, semierecto. No ha sido posible evaluarlo, ni asignarle una categoría.

\section{Haageocereus tenuis F. Ritter}

Publicación: Kakteen Sudamer. 4: 1421. 1981.

Colección tipo: F. Ritter 569

Herbarios:

Nombre común: D esconocido.

Registro departamental: LI.

Regiones Ecológicas: DST; 0-500 m.

SINANPE: Sin registro.

Herbarios peruanos: USM (2).

Observaciones: Cactus arbustivo, postrado. No ha sido posible evaluarlo, ni asignarle una categoría.

\section{Haageocereus versicolor(Wenderm. \& Backeb.) Backeb.}

Publicación: Blatt. Kakteenf. 1936.

Colección tipo: C. Backeberg s.n.

Herbarios:

Nombre común: D esconocido.

Registro departamental: LA, PI, TU.

Regiones Ecológicas: DCT, MDE; $0-$ $1500 \mathrm{~m}$.

SINANPE: Sin registro.

Henbarios penuanos: USM (2).

Observaciones: Cactus arbustivo, columnar o decumbente. No ha sido posible evaluarlo, ni asignarle una categoría.

\section{Haageocereus vulpes F. Ritter}

Publicación: Kakteen Sudamer. 4: 1423. 1981.

Colección tipo: F. Ritter 1059

Herbarios:

Nombre común: D esconocido.

Registro departamental: LI.

Regiones Ecológicas: D ST; 0-500 m.

SINAN PE: Sin registro.

Herbarios peruanos: Ninguno.

Observaciones: Cactus arbustivo, columnar, hasta $2 \mathrm{~m}$ de alto. No ha sido posible evaluarlo, ni asignarle una categoría.

\section{Haageocereus zangalensis F. Ritter}

Publicación: Kakteen Sudamer. 4: 1424. 1981.

Colección tipo: F. Ritter 1074

Herbarios:

Nombre común: D esconocido.

Registro departamental: CA.

Regiones Ecológicas: MDE; 1500- 2000

m.

SINAN PE: Sin registro.

Hembarios peruanos: Ninguno.

Observaciones: Cactus arbustivo, decumbente. No ha sido posible evaluarlo, ni asignarle una categoría.

\section{Hylocereus penuvianus Backeb.}

Publicación: Blätt. Kakteenf. 7(Nacht.): 15. 1937.

Colección tipo: C. Reynel et al. 3238

Herbarios:

Nombre común: D esconocido.

Registro departamental: CA, LA, PI.

Regiones Ecológicas: DCT; $400 \mathrm{~m}$.

SINANPE: Sin registro.

Herbarios peruanos: Ninguno.

Observaciones: Cactus leñoso trepador. Esta es una especie poco estudiada. No ha sido posible evaluarlo, ni asignarle una categoría.

\section{Lasiocereus fulvus F. Ritter}

Publicación: Kakteen Sudamer. 4: 1479. 1981.

Colección tipo: F. Ritter 1303

Herbarios: U.

Nombre común: D esconocido.

Registro departamental: AM.

Regiones Ecológicas: MDE; 500- 1700

$\mathrm{m}$.

SINANPE: Sin registro.

Herbarios peruanos: USM (3)

Observaciones: Cactus arbustivo, hasta $3 \mathrm{~m}$. No ha sido posible evaluarlo, ni asignarle una categoría. 


\section{Lasioceneus rupicola F. Ritter}

Publicación: Kakteen Sudamer. 4: 1478. 1981.

Colección tipo: F. Ritter 661

Herbarios: U.

Nombre común: D esconocido.

Registro departamental: CA.

Regiones Ecológicas: MDE; 2000- 2600

$\mathrm{m}$.

SINANPE: Sin registro.

Herbarios peruanos: USM (3).

Observaciones: Cactus arbustivo, hasta $4 \mathrm{~m}$. No ha sido posible evaluarlo, ni asignarle una categoría.

\section{Lepismium brevispinum Barthlott}

Publicación: Bradleya 5: 99. 1987.

Colección tipo: W. Rauh 27

Herbarios:

Nombre común: D esconocido.

Registro departamental: AM.

Regiones Ecológicas: MDE, BS; 1500$2000 \mathrm{~m}$.

SINANPE: Sin registro.

Herbarios peruanos: USM (3).

Observaciones: Cactus arbustivo, hasta $2 \mathrm{~m}$. No ha sido posible evaluarlo, ni asignarle una categoría.

\section{Lepismium micranthum (Vaupel) Barthlott}

Publicación: Bradleya 5: 99. 1987.

Colección tipo: A. Weberbauer 1353

Herbarios: US.

Nombre común: D esconocido.

Registro departamental: PU.

Regiones Ecológicas: BMHM; $2100 \mathrm{~m}$.

SINANPE: Sin registro.

Herbarios peruanos: Ninguno.

Observaciones: Cactus arbustivo, erecto a péndulo. No ha sido posible evaluarlo, ni asignarle una categoría.

\section{Loxanthoceneus sulciferRauh \& Backeb.}

Publicación: D escr. Cact. Nov. 14. 1956. Colección tipo: W. Rauh 52

Herbarios:

Nombre común: D esconocido.

Registro departamental: AN, CA, LL.

Regiones Ecológicas: MDE; 1000 - 3500

$\mathrm{m}$

SINAN PE: Sin registro.

Herbarios peruanos: Ninguno.

Observaciones: Cactus trepador o postrado. No ha sido posible evaluarlo, ni asignarle una categoría.

\section{Loxanthocereus deserticola F. Ritter}

Publicación: Kakteen Sudamer. 4: 1458. 1981. Colección tipo: F. Ritter 185

Herbarios:

Nombre común: Desconocido.

Registro departamental: AY, IC.

Regiones Ecológicas: MDE; 1500-2000 m.

SINAN PE: Sin registro.

Hemarios peruanos: Ninguno.

Observaciones: Ostolaza (1998b) y Hunt (1999) lo consideran, con duda, un sinónimo de Cleistocactus davispinus; de acuerdo a Hunt (1999), probablemente sea híbrido entre Cleistocactus sp. y H aageocereus sp. No ha sido posible evaluarlo, ni asignarle una categoría.

\section{Loxanthocereus erectispinus Rauh \& Backeb.}

Publicación: Descr. Cact. Nov. 15. 1956.

Colección tipo: W. Rauh 98

Herbarios:

Nombre común: D esconocido.

Registro departamental: AN.

Regiones Ecológicas: MDE; 1500-2500

m.

SINAN PE: Sin registro.

Herbarios peruanos: Ninguno.

Observaciones: Hunt (1999) la considera un probable híbrido entre Cleistocactus sp. y E spostoa sp. No ha sido posible evaluarlo, ni asignarle una categoría.

\section{Loxanthocereus hoffmannii F. Ritter}

Publicación: Kakteen Sudamer. 4: 1461. 1981. Colección tipo: Hoffmann s.n.

Herbarios:

Nombre común: D esconocido.

Registro departamental: LI.

Regiones Ecológicas: D ST; 0-500 m.

SINANPE: Sin registro.

Hembarios peruanos: Ninguno.

Observaciones: Hunt (1999) la considera un probable híbrido entre Cleistocactus sp. y E spostoa sp. El nombre de este taxón requiere revisarse, pues podría ser un nombre inválido de acuerdo a Eggli y Taylor (1992). No ha sido posible evaluarlo, ni asignarle una categoría.

134. Matucana aurantiaca (Vaupel) Buxb. subsp. aurantiaca

Publicación:

Colección tipo: A. Weberbauer 3846

Herbarios:

Nombre común: D esconocido.

Registro departamental: CA, LL.

Regiones Ecológicas: MDE; 2000- 2500

m.

SINAN PE: Sin registro.

Herbarios penuanos: CPUN (1), USM (3).

Observaciones: Cactus usualmente solitario de hasta $35 \mathrm{~cm}$ de alto. No ha sido posible evaluarlo, ni asignarle una categoría. 
135. Matucana aurantiaca (Vaupel) Buxb. subsp. currundayensis (F. Ritter) Mottram 1997

Publicación: Die Kakteen 1, 9. 1973.

Colección tipo: F. Ritter 164

Herbarios: U, SG O, ZSS.

Nombre común: D esconocido.

Registro departamental: AN, CA, LL.

Regiones Ecológicas: MDE; 2000-2500

m.

SINAN PE: Sin registro.

Herbarios peruanos: USM (1).

Observaciones: Cactus arbustivo conocido de por lo menos cuatro localidades. No ha sido posible evaluarlo, ni asignarle una categoría.

\section{Matucana aureiflora F. Ritter}

Publicación: Kakteen Sukk. 16: 229. 1965.

Colección tipo: F. Ritter 1310

Herbarios: U.

Nombre común: D esconocido.

Registro departamental: CA.

Regiones Ecológicas: MA; 2900 m.

SINANPE: Sin registro.

Herbarios peruanos: Ninguno.

Observaciones: Esta especie se conoce de la cuenca del río Cajamarca. No ha sido posible evaluarla, ni asignarle una categoría.

\section{Matucana formosa F. Ritter}

Publicación: Taxon 12(3): 125. 1963.

Colección tipo: F. Ritter 658

Herbarios:

Nombre común: D esconocido.

Registro departamental: CA, LL.

Regiones Ecológicas: MDE, BS; 500$1000 \mathrm{~m}$.

SINAN PE: Sin registro.

Herbarios peruanos: Ninguno.

Observaciones: Cactus globoso. No ha sido posible evaluarlo, ni asignarle una categoría.

138. Matucana fruticosa F. Ritter

Publicación: Succulenta (Netherlands) 45(8): 117. 1966.

Colección tipo: F. Ritter 1307

Herbarios:

Nombre común: D esconocido.

Registro departamental: CA.

Regiones Ecológicas: MDE; 1500-2500

$\mathrm{m}$.

SINAN PE: Sin registro.

Herbarios peruanos: Ninguno.

Observaciones: Cactus arbustivo. No ha sido posible evaluarlo, ni asignarle una categoría.

\section{Matucana hastifera F. Ritter}

\section{NE}

Publicación: Kakteen Sudamer. 4: 1496. 1981.

Colección tipo: F. Ritter 1306

Herbarios:

Nombre común: D esconocido.

Registro departamental: AN.

Regiones Ecológicas: MA; 3000-3500 $\mathrm{m}$.

SINANPE: Sin registro.

Herbarios peruanos: Ninguno.

Observaciones: De acuerdo a Hunt (1999) es sinónimo de Matucana aurantiaca subsp. aurrundayensis. O stolaza la considera una buena especie (2005 com. pers.). No ha sido posible evaluarlo, ni asignarle una categoría.

\section{Matucana haynei (Otto ex Salm-Dyck) Britton \& Rose}

Publicación: 1922.

Colección tipo: J.N. Rose 18651

Herbarios:

Nombre común: Desconocido.

Registro departamental: LI.

Regiones Ecológicas: MA, PSH; 2000-

$3000 \mathrm{~m}$.

SINAN PE: Sin registro.

Herbarios peruanos: USM (5).

Observaciones: Cactus globoso. No ha sido posible evaluarlo, ni asignarle una categoría.

141. Matucana haynei (0 tto ex Salm-Dyck) Britton \&

Rose subsp. herzogiana (Backeb.)

Mottram 1997

Publicación: Cact. 3: 102-103, f. 109.

1922.

Colección tipo:

Herbarios:

Nombre común: D esconocido.

Registro departamental: AN.

Regiones Ecológicas: MDE, MA; 2000$3000 \mathrm{~m}$.

SINANPE: PNH

Herbarios peruanos: USM (2).

Observaciones: Cactus globoso conocido del centro del país. No ha sido posible evaluarlo, ni asignarle una categoría.

142. Matucana haynei (0tto ex Salm-Dyck) Britton \& Rose subsp. hystrix (Rauh \& Backeb.) Mottram 1997

Publicación: Cact. 3: 102-103, f. 109. 1922. Colección tipo: W. Rauh K113

Herbarios: SG O, ZSS.

Nombre común: Desconocido.

Registro departamental: $A R, A Y$.

Regiones Ecológicas: MDE, MA; 2000$3000 \mathrm{~m}$

SINANPE: Sin registro.

Herbarios penuanos: USM (1). 
Observaciones: Cactus globoso conocido del sur del país. No ha sido posible evaluarlo, ni asignarle una categoría.

\section{Matucana haynei (0tto ex Salm-Dyck) Britton \& Rose subsp. myriacantha (Vaupel) Mottram 1997}

Publicación: Cact. 3: 102-103, f. 109. 1922.

Colección tipo: A. Weberbauer 4272

Herbarios: U, SG O, ZSS.

Nombre común: Desconocido.

Registro departamental: AM, CA, LL.

Regiones Ecológicas: MDE, MA; 1500— $3500 \mathrm{~m}$.

SINAN PE: PNH

Herbarios peruanos: Ninguno.

Observaciones: Cactus de tallo corto. Este taxón se halla en cultivo en Jardín Botánico San Marcos (Cajamarca). No ha sido posible evaluarlo, ni asignarle una categoría.

\section{Matucana huagalensis (Donald \& A.B. Lau) Bregman}

Publicación: Succulenta (Netherlands) 67(7-8): 155. 1988.

Colección tipo: Lau 174

Herbarios:

Nombre común: Desconocido.

Registro departamental: CA.

Regiones Ecológicas: MDE; 2000- $2500 \mathrm{~m}$.

SINANPE: Sin registro.

Herbarios peruanos: Ninguno.

Observaciones: Cactus globoso a cilíndrico usualmente solitario. No ha sido posible evaluarlo, ni asignarle una categoría.

145. Matucana hystrix Rauh \& Backeb.

Publicación: Descr. Cact. Nov. 19. 1956.

Colección tipo: W. Rauh 113

Herbarios:

Nombre común: Desconocido.

Registro departamental: AY.

Regiones Ecológicas: MA, PSH; 3000-

$4000 \mathrm{~m}$.

SINANPE: Sin registro.

Herbarios peruanos: Ninguno.

Observaciones: Cactus globoso a cilíndrico usualmente solitario.

No ha sido posible evaluarlo, ni asignarle una categoría.

146. Matucana intertexta F. Ritter

Publicación: Taxon 12(3): 125. 1963.

Colección tipo: F. Ritter 693

Herbarios:

Nombre común: D esconocido.

Registro departamental: CA.

Regiones Ecológicas: MDE; 2000- 2600

$\mathrm{m}$.

SINANPE: Sin registro.

Herbarios penuanos: USM (3).
Observaciones: Cactus globoso a cilíndrico usualmente solitario. No ha sido posible evaluarlo, ni asignarle una categoría.

\section{Matucana krahnii (Donald) Bregmann}

Publicación: Kakteen Sukk. 37(12): 253.

1986.

Colección tipo: P.C. Hutchison \& Krahn

4954

Herbarios:

Nombre común: D esconocido.

Registro departamental: AM.

Regiones Ecológicas: MA, PSH; 1500 $2000 \mathrm{~m}$.

SINAN PE: Sin registro.

Hembarios peruanos: Ninguno.

Observaciones: Cactus globoso a cilíndrico usualmente solitario. No ha sido posible evaluarlo, ni asignarle una categoría.

148. Matucana madisonionum (H utchison) G.D. Rowley

Publicación: Repert. Pl. Succ. 22: 10. 1971. Colección tipo: P.C. Hutchison 1521

Herbarios: UC, US.

Nombre común: Desconocido.

Registro departamental: AM.

Regiones Ecológicas: BS; $400 \mathrm{~m}$.

SINAN PE: Sin registro.

Herbarios peruanos: Ninguno.

Observaciones: Cactus globoso a cilíndrico usualmente solitario. No ha sido posible evaluarlo, ni asignarle una categoría.

\section{Matucana oreodoxa (F. Ritter) Slaba}

Publicación: Kaktusy 22(6): 130. 1986.

Colección tipo: F. Ritter s.n.

Herbarios:

Nombre común: D esconocido.

Registro departamental: AN.

Regiones Ecológicas: MA; 2500-3000

m.

SINANPE: Sin registro.

Herbarios peruanos: Ninguno.

Observaciones: Cactus globoso a cilíndrico usualmente solitario. No ha sido posible evaluarlo, ni asignarle una categoría.

\section{Matucana paucicostata F. Ritter}

Publicación: Taxon 12(3): 124- 125.

1963.

Colección tipo: F. Ritter 597

Herbarios:

Nombre común: D esconocido.

Registro departamental: AN.

Regiones Ecológicas: MDE; 2000- 2500

$\mathrm{m}$.

SINANPE: Sin registro.

Henbarios peruanos: Ninguno.

Observaciones: Cactus globoso a cilíndrico usualmente solitario. No ha sido posible evaluarlo, ni asignarle una categoría. 
151. Matucana polzii L. Diers, Donald \& E. Zecher

Publicación: Kakteen Sukk. 37(6): 118.

1986.

Colección tipo: Zecher 762

Herbarios:

Nombre común: D esconocido.

Registro departamental: Sin datos.

Regiones Ecológicas: MDE; 2100-2300

m.

SINAN PE: Sin registro.

Hembarios peruanos: Ninguno.

Observaciones: Cactus globoso a cilíndrico usualmente solitario. No ha sido posible evaluarlo, ni asignarle una categoría.

\section{Matucana pujupatii (Donald \& A.B. Lau) Bregmann}

Publicación: Willdenowia 17(1): 179 1988

Colección tipo: Lau 107

Herbarios:

Nombre común: D esconocido.

Registro departamental: CA.

Regiones Ecológicas: MDE; 0-500 m.

SINAN PE: Sin registro.

Herbarios peruanos: USM (1).

Observaciones: Cactus globoso a cilíndrico usualmente solitario. No ha sido posible evaluarlo, ni asignarle una categoría.

\section{Matucana nitteri Buining}

Publicación: Succulenta (Netherlands) 1 :

2. 1959.

Colección tipo: F. Ritter 299

Herbarios:

Nombre común: D esconocido.

Registro departamental: LI.

Regiones Ecológicas: MDE; 2000- 2500

m.

SINAN PE: Sin registro.

Herbarios peruanos: Ninguno.

Observaciones: Cactus globoso a cilíndrico usualmente solitario. No ha sido posible evaluarlo, ni asignarle una categoría.

\section{Matucana tuberculata (Donald) Bregmann}

Publicación: Succulenta (Netherlands) 66(9): 175. 1987.

Colección tipo: P.C. Hutchison 6218

Herbarios:

Nombre común: Desconocido.

Registro departamental: LL.

Regiones Ecológicas: MDE; 1500- 2500

$\mathrm{m}$.

SINAN PE: Sin registro.

Herbarios peruanos: Ninguno.

Observaciones: Cactus globoso a cilíndrico usualmente solitario. No ha sido posible evaluarlo, ni asignarle una categoría.
155. Matucana weberbaueni (Vaupel) Backeb.

Publicación: Beitr. Sukkulentenk. Sukkulentenpflege 1939: 42. 1939.

Colección tipo: A. Weberbauer 4271

Herbarios: US.

Nombre común: D esconocido.

Registro departamental: AM.

Regiones Ecológicas: BS; 2000- 2500 m.

SINANPE: Sin registro.

Herbarios peruanos: Ninguno.

Observaciones: Cactus globoso a cilíndrico usualmente solitario. No ha sido posible evaluarlo, ni asignarle una categoría.

\section{Matucana mirabilis Buining}

\section{DD}

Publicación: Sukkulentenkunde 7-8: 39. 1963.

Colección tipo: Ackers s.n.

Herbarios:

Nombre común: D esconocido.

Registro departamental: LI.

Regiones Ecológicas: MA; 2500-3000 m.

SINANPE: Sin registro.

Herbarios peruanos: Ninguno.

Observaciones: Cactus globoso o cilíndrico que crece en grupos. Hunt (1992) sugirió que se trataba de un híbrido entre Cleistocactus fieldianus y Matucana supertex ta. Ha sido transferida al notogénero x Cleistocana mirabilis (Hunt 1999), aunque no fue tratada por Anderson (2001)

\section{Melocactus bellavistensis Rauh \& Backeb. subsp.} onychacanthus (F. Ritter) N. Taylor

Publicación: Bradleya 9: 66. 1991.

Colección tipo: F. Ritter 700

Herbarios:

Nombre común: D esconocido.

Registro departamental: AM, CA, LL.

Regiones Ecológicas: MDE; 1000— 2000 m.

SINAN PE: Sin registro.

Herbarios peruanos: Ninguno.

Observaciones: Cactus globoso a cilíndrico usualmente solitario. No ha sido posible evaluarlo, ni asignarle una categoría.

158. Mila caespitosa Britton \& Rose

Publicación: Cact. 3: 211-212, pl. 22, f. 2. 1922

Colección tipo: J.N. Rose 18555

Hembarios: US

Nombre común: D esconocido.

Registro departamental: LI.

Regiones Ecológicas: DST, MDE; 420-

$1100 \mathrm{~m}$.

SINANPE: Sin registro.

Herbarios peruanos: USM (7).

Observaciones: Cactus globoso a cilíndrico. Esta especie es una de las representantes de este género endémico, con necesidad de una revisión taxonómica. Algunas de sus subpoblaciones están afectadas por la expansión urbana de la ciudad de Lima. No ha sido posible evaluarlo, ni asignarle una categoría. 


\section{Mila colorea F. Ritter}

Publicación: Kakteen Sudamer. 4: 1341. 1981.

Colección tipo: F. Ritter 699

Herbarios:

Nombre común: D esconocido.

Registro departamental: AN.

Regiones Ecológicas: MDE; 2000- 2500

$\mathrm{m}$.

SINANPE: Sin registro.

Herbarios peruanos: Ninguno.

Observaciones: Aceptada provisionalmente por Hunt (1999), pero considerada por O stolaza (2005 com. pers.) como sinónimo de Mila pugionifera , mientras que Anderson (2001) la considera de Mila caespitosa. No ha sido posible evaluarlo, ni asignarle una categoría.

\section{Mila nealeana Backeb.}

Publicación: Blatt. Kakteenf. 1(1):2. 1934. Colección tipo: C. Backeberg s.n.

Herbarios:

Nombre común: D esconocido.

Registro departamental: LI.

Regiones Ecológicas: MDE; 1000-2500 m.

SINAN PE: Sin registro.

Herbarios peruanos: Ninguno.

Observaciones: Aceptada por Hunt (1999) y Ostolaza (2005 com. pers.), pero considerada sinónimo de Mila caespitosa por Anderson (2001). No ha sido posible evaluarlo, ni asignarle una categoría.

\section{Neoraimondia arequipensis Backeb.}

Publicación: Blatt. Kakteenf. 1936. .

Colección tipo: Meyer s.n.

Herbarios:

Nombre común: Gigantón.

Registro departamental: AR, IC, LI.

Regiones Ecológicas: MDE; $700 \mathrm{~m}$.

SINAN PE: Sin registro.

Herbarios penuanos: HAO (2), HUSA (3), USM (6).

Observaciones: Cactus arbustivo. No ha sido posible evaluarlo, ni asignarle una categoría.

162 Neoraimondia arequipensis Backeb. subsp. roseiflora (Werdermann \& Backeb.) Ostolaza

\section{LC}

Publicación: Cactaceae Consensus Initiatives, 6: 9. 1998.

Colección tipo:

Herbarios:

Nombre común: Desconocido.

Registro departamental: AY, CA, HV, IC, LL, LI.

Regiones Ecológicas: DST, MDE; 500— $1500 \mathrm{~m}$.

SINANPE: Sin registro.

Herbarios peruanos: HUT (1), USM (5).
Observaciones: Cactus arbustivo conocido de varias localidades en valles interandinos.

163. Neowerdermannia chilensis Backeberg subsp. peruviana (F. Ritter) Ostolaza 1998

$$
\text { EN, A2; D }
$$

Publicación: Cactaceae Consensus Initiatives, 6: 9. 1998.

Colección tipo: F. Ritter 191

Herbarios: U, ZSS.

Nombre común: Desconocido.

Registro departamental: MO, TA.

Regiones Ecológicas: PD; $3500-4000$ $\mathrm{m}$.

SINANPE: Sin registro.

Herbarios peruanos: USM (1).

Observaciones: Cactus globoso aparentemente restringido al sur del país. El ejemplar tipo proviene de un área influenciada por actividad minera.

\section{Opuntia apurimacensis (F. Ritter) R. Crook \& Mottram}

Publicación: Bradleya 13: 100. 1995.

Colección tipo: F. Ritter 1323

Herbarios:

Nombre común: D esconocido.

Registro departamental: AP.

Regiones Ecológicas: MDE; 2000- 2500

m.

SINAN PE: Sin registro.

Herbarios peruanos: Ninguno.

Observaciones: Cactus arbustivo semipostrado a erecto, hasta 1 $\mathrm{m}$ de alto. No ha sido posible evaluarlo, ni asignarle una categoría.

\section{Opuntia blancii (Backeb.) G.D. Rowley}

Publicación: Natl. Cact. Succ. J. 13(1):5. 1958.

Colección tipo: Blanc s.n.

Herbarios:

Nombre común: D esconocido.

Registro departamental: AN.

Regiones Ecológicas: MA, PSH; 3500$4000 \mathrm{~m}$.

SINAN PE: Sin registro.

Herbarios peruanos: Ninguno.

Observaciones: Cactus que forma almohadillados. No ha sido posible evaluarlo, ni asignarle una categoría.

166. Opuntia corotilla K. Schum. ex Vaupel

Publicación: Bot. Jahrb. Syst. 50(2-3, Beibl. 111):28-29. 1913.

Colección tipo: A. Weberbauer 1412

Herbarios:

Nombre común: Desconocido.

Registro departamental: AR.

Regiones Ecológicas: MA, PSH; 3000$3500 \mathrm{~m}$.

SINAN PE: RNS

Herbarios peruanos: HUSA (4), USM (2). 
Observaciones: Cactus frágil de segmentos subglobosos a elongados. No ha sido posible evaluarlo, ni asignarle una categoría.

\section{Opuntia crassicylindrica (Rauh \& Backeb.) G.D. Rowley}

Publicación: Natl. Cact. Succ. J. 13(1):5.

1958.

Colección tipo: W. Rauh 152

Herbarios:

Nombre común: D esconocido.

Registro departamental: AN.

Regiones Ecológicas: D ST, MDE; 500$1500 \mathrm{~m}$.

SINANPE: Sin registro.

Hembarios peruanos: Ninguno.

Observaciones: Cactus laxo de segmentos alargados a cilíndricos. No ha sido posible evaluarlo, ni asignarle una categoría.

\section{Opuntia fulvicoma (Rauh \& Backeb.) G.D. Rowley}

Publicación: Natl. Cact. Succ. J. 13(1):5. 1958.

Colección tipo: W. Rauh 122

Herbarios:

Nombre común: D esconocido.

Registro departamental: AN.

Regiones Ecológicas: MA; 3000-3500

$\mathrm{m}$.

SINAN PE: Sin registro.

Herbarios peruanos: Ninguno.

Observaciones: Cactus que forma cojines. No ha sido posible evaluarlo, ni asignarle una categoría.

\section{Opuntia hirschii (Backeb.) G.D. Rowley}

Publicación: Natl. Cact. Succ. J. 13(1):5. 1958.

Colección tipo: W. Rauh 103

Herbarios:

Nombre común: D esconocido.

Registro departamental: AN.

Regiones Ecológicas: MA, PSH; 3500$4000 \mathrm{~m}$.

SINAN PE: Sin registro.

Herbarios peruanos: Ninguno.

Observaciones: Cactus globoso o cilíndrico. No ha sido posible evaluarlo, ni asignarle una categoría.

\section{Opuntia mistiensis (Backeb.) G.D. Rowley}

Publicación: Natl. Cact. Succ. J. 13(1):5. 1958.

Colección tipo: C. Backeberg s.n.

Herbarios:

Nombre común: D esconocido.

Registro departamental: AR.

Regiones Ecológicas: MA, PSH; 3500-

$4000 \mathrm{~m}$.

SINAN PE: Sin registro.

Herbarios penuanos: HUSA (2).
Observaciones: Cactus semipostrado. No ha sido posible evaluarlo, ni asignarle una categoría.

\section{Opuntia punta-caillan (Rauh \& Backeb.) G.D. Rowley}

Publicación: Natl. Cact. Succ. J. 13(1):5. 1958.

Colección tipo: W. Rauh 105

Herbarios:

Nombre común: D esconocido.

Registro departamental: AN.

Regiones Ecológicas: PSH, AA; 4000$4500 \mathrm{~m}$.

SINANPE: Sin registro.

Herbarios peruanos: Ninguno.

Observaciones: Cactus que forma almohadillados. No ha sido posible evaluarlo, ni asignarle una categoría.

\section{Opuntia pyrmacantha K. Schum.}

Publicación: Gesamtbeschr. Kakt. 694. 1898.

Colección tipo: A. Stübel 98c, 111b

Herbarios:

Nombre común: D esconocido.

Registro departamental: TA.

Regiones Ecológicas: PD ; 4000-4500 m.

SINAN PE: Sin registro.

Herbarios peruanos: Ninguno.

Observaciones: Este taxón fue considerado en Brako \& Zarucchi (1993) como un endemismo; sin embargo, no ha sido posible evaluarlo, ni asignarle una categoría.

\section{Opuntia staffordae Bullock}

\section{DD}

Publicación: Cact. J. (London) 8:15. 1939. Colección tipo: D. Stafford 1030

Herbarios: K.

Nombre común: D esconocido.

Registro departamental: AR.

Regiones Ecológicas: Sin datos; altitud desconocida.

SINAN PE: Sin registro.

Herbarios peruanos: Ninguno.

Observaciones: Cactus que forma almohadillados, de taxonomía dudosa. No ha sido posible evaluarlo, ni asignarle una categoría..

174. Opuntia unguispina Backeb.

Publicación: Blatt. Kakteenf. 1937-7, gen. 10, sp. 7. 1937.

Colección tipo: F. Ritter 121b

Herbarios:

Nombre común: D esconocido.

Registro departamental: AR.

Regiones Ecológicas: D ST, MDE; 500$2000 \mathrm{~m}$.

SINANPE: Sin registro.

Herbarios penuanos: HUSA (1). 
Observaciones: Cactus postrado o semierecto. No ha sido posible evaluarlo, ni asignarle una categoría.

\section{Opuntia yanganucensis (Rauh \& Backeb.) G.D. Rowley}

Publicación: Natl. Cact. Succ. J. 13(1):5. 1958.

Colección tipo: F. Ritter 99

Herbarios:

Nombre común: Desconocido.

Registro departamental: AN.

Regiones Ecológicas: MA, PSH; 3000$4000 \mathrm{~m}$.

SINANPE: PNH

Herbarios peruanos: Ninguno.

Observaciones: Cactus que forma cojines. No ha sido posible evaluarlo, ni asignarle una categoría.

\section{Opuntia zehndeni (Rauh \& Backeb.) G.D. Rowley}

Publicación: Natl. Cact. Succ. J. 13:6. 1958.

Colección tipo: W. Rauh 121

Herbarios:

Nombre común: Desconocido.

Registro departamental: AY.

Regiones Ecológicas: MA; 3000-3500 m.

SINAN PE: Sin registro.

Herbarios peruanos: USM (1).

Observaciones: Cactus que forma cojines. No ha sido posible evaluarlo, ni asignarle una categoría.

\section{Oreocereus doelzianus (Backeb.) Borg}

Publicación: Cacti 115. 1937.

Colección tipo: C. Backeberg s.n.

Herbarios:

Nombre común: D esconocido.

Registro departamental: AY, HV.

Regiones Ecológicas: MD E; 2500-3000

$\mathrm{m}$.

SINAN PE: Sin registro.

Herbarios peruanos: USM (1).

Observaciones: Cactus ramificado desdela base. No ha sido posible evaluarlo, ni asignarle una categoría.

\section{Oreocereus ritteri Cullman}

Publicación: Kakteen Sukk. 7:101, 103. 1958.

Colección tipo: F. Ritter 177a

Herbarios:

Nombre común: D esconocido.

Registro departamental: AY.

Regiones Ecológicas: MA, PSH; 3000-

$4000 \mathrm{~m}$.

SINANPE: Sin registro.

Herbarios peruanos: Ninguno.

Observaciones: Cactus arborescente. No ha sido posible evaluarlo, ni asignarle una categoría.

\section{Oreoceneus tacnaensis F. Ritter}

Publicación: Kakteen Sudamer. 4:1363.

1981.

Colección tipo: F. Ritter 124

Herbarios:

Nombre común: D esconocido.

Registro departamental: TA.

Regiones Ecológicas: MA; 2500-3200

m.

SINAN PE: Sin registro.

Herbarios penuanos: USM (2).

Observaciones: Cactus arborescente. No ha sido posible evaluarlo, ni asignarle una categoría.

\section{Oroya borchersii (Boed.) Backeb.}

\section{VU, B lab(iii)}

Publicación: Stizungsber. Heidelberger Akad. Wiss., Math.-Naturwiss. Kl. 487. 1958.

Colección tipo: F. Ritter 163

Herbarios: U.

Nombre común: D esconocido.

Registro departamental: AN.

Regiones Ecológicas: AA; 4100-4250 m.

SINANPE: PNH

Hemarios penuanos: HUT (2), USM (6).

Observaciones: Cacto subesférico de flores amarillas, conocido de localidades dispersas en la cuenca del Santa. Actividades mineras han impactado algunas de sus subpoblaciones, si bien se han realizado esfuerzos por recuperarlas.

\section{Oroya penuviana (K. Schum.) Britton \& Rose}

\section{NT}

Publicación: Cact. 3: 102. 1922.

Colección tipo: W. Rauh 3

Herbarios: ZSS.

Nombre común: D esconocido.

Registro departamental: $\mathrm{AP}, \mathrm{AY}, \mathrm{CU}, \mathrm{HV}$, JU, LI.

Regiones Ecológicas: PSH; 3500-4200 m.

SINANPE: Sin registro.

Herbarios peruanos: HUSA (1), USM (6).

Observaciones: Cactus globoso, conocido de numerosas localidades en el centro del país. Esta especie habita pajonales y laderas rocosas, afectadas ya sea por pastoreo intensivo, incendios intencionales 0 actividades mineras.

\section{Pereskia horrida DC.}

Publicación: Prodr. 3: 475. 1828.

Colección tipo: A. Humboldt \& A. Bonpland 3594

Herbarios: P-Bonpl..

Nombre común: D esconocido.

Registro departamental: AM, CA, LL.

Regiones Ecológicas: BS; 450-580 m.

SINAN PE: Sin registro.

Herbarios peruanos: HUT (3).

Observaciones: Cactus arbustivo 0 arbóreo, hasta $6 \mathrm{~m}$ de alto. No ha sido posible evaluarlo, ni asignarle una categoría. 
183. Platyopuntia infesta F. Ritter

Publicación: Kakteen Sudamer. 4:1258.

1981.

Colección tipo: F. Ritter 309

Herbarios:

Nombre común: D esconocido.

Registro departamental: AN.

Regiones Ecológicas: MDE, MA; 2500$3000 \mathrm{~m}$.

SINANPE: Sin registro.

Herbarios peruanos: Ninguno.

Observaciones: Cactus arbustivo, muchas ramas semierectas, hasta $50 \mathrm{~cm}$ de alto. No ha sido posible evaluarlo, ni asignarle una categonáa

\section{Praeceneus euchlorus (F. A. C. Weber) N. P. Taylor subsp. jaenensis (Rauh \& Backeb.) Ostolaza}

\section{LC}

Publicación: Cactaceae Consensus Initiatives, 6: 9. 1998.

Colección tipo: W. Rauh 78

Herbarios:

Nombre común: D esconocido.

Registro departamental: AM, CA, SM.

Regiones Ecológicas: BS; 500-1000 m.

SINAN PE: Sin registro.

Hembarios peruanos: USM (4).

Observaciones: Cactus erecto, conocido de por lo menos seis poblaciones en el norte del país, la mayoría de ellas de la cuenca del Marañón.

\section{Pygmaeocereus bieblii Diers}

Publicación: Kakteen Suk. 46(11): 256260. 1995.

Colección tipo:

Herbarios: KOELN (BIE 89-1).

Nombre común: D esconocido.

Registro departamental: AN.

Regiones Ecológicas: Sin datos; altitud desconocida.

SINAN PE: Sin registro.

Herbarios peruanos: Ninguno.

Observaciones: Cactus diminuto, globoso, solitario, hasta $5 \mathrm{~cm}$ de alto. No ha sido posible evaluarlo, ni asignarle una categoría.

\section{Pygmaeocereus bylesianus Andreae \& Backeb.}

Publicación: Natl. Cact. Succ. J. 12(4):86 1957.

Colección tipo: Andreae s.n.

Herbarios:

Nombre común: D esconocido.

Registro departamental: Sin datos.

Regiones Ecológicas: D ST; 0-1000 m.

SINAN PE: Sin registro.

Hembarios peruanos: Ninguno.

Observaciones: Cactus de tallo corto cilíndrico, hasta $8 \mathrm{~cm}$ de alto. No ha sido posible evaluarlo, ni asignarle una categoría.

\section{Pygmaeocereus familiaris F. Ritter}

Publicación: Kakteen Sudamer. 4:1428. 1981.

Colección tipo: F. Ritter 322

Herbarios:

Nombre común: D esconocido.

Registro departamental: AR.

Regiones Ecológicas: D ST; 0-500 m.

SINANPE: Sin registro.

Herbarios penuanos: USM (2).

Observaciones: Cactus de hasta $2 \mathrm{~cm}$ de alto. No ha sido posible evaluarlo, ni asignarle una categoría

188. Rauhocereus niosaniensis Backeb. subsp. jaenensis (Rauh) C. Ostolaza

\author{
Publicación: \\ Colección tipo: \\ Herbarios: \\ Nombre común: Desconocido. \\ Registro departamental: CA. \\ Regiones Ecológicas: BS; 500-1000 m. \\ SINAN PE: Sin registro. \\ Herbarios penuanos: USM (1)
}

Observaciones: Cactus arbustivo erecto, hasta $4 \mathrm{~m}$ de alto. No ha sido posible evaluarlo, ni asignarle una categoría.

\section{Weberbauerocereus chuninensis F. Ritter}

EN, Blab(iii)

Publicación: Kakteen Sukk. 8:133. 1962. Colección tipo: F. Ritter 685

Henbarios: U.

Nombre común: D esconocido.

Registro departamental: LI.

Regiones Ecológicas: MA; 2500-3000 $\mathrm{m}$.

SINAN PE: Sin registro.

Herbarios penuanos: USM (4).

Observaciones: Cactus arbustivo, más o menos erecta, hasta $4 \mathrm{~m}$. Está cercanamente relacionada a W eberbauerocereus winterianus. Se conocía sólo de la localidad tipo (Churín), donde la única población observada ha disminuido en por lo menos $50 \%$. D os nuevas poblaciones han sido localizadas recientemente en la Provincia de Oyón. Estas últimas poblaciones no se encuentran amenazadas y poseen individuos mucho más robustos y longevos que los encontrados en Churín; sin embargo, consideramos que esta especie se encuentra en peligro ya que sus poblaciones cubren un área muy restringida, cercana a centros poblados. 


\section{Weberbaueroceneus cuzcoensis Knize}

LC

Publicación: Biota 7(57): 256. 1968.

Colección tipo: K. Knize 918

Herbarios: SMF.

Nombre común: Desconocido.

Registro departamental: AP, AY, CU, HV. Regiones Ecológicas: MDE, MA; 500$2000 \mathrm{~m}$.

SINANPE: Sin registro.

H erbarios peruanos: HUSA (1), SMF (isotipo), USM (4).

Observaciones: Cactus arborescente, muy ramificado, hasta aproximadamente $6 \mathrm{~m}$ de alto. Aceptada provisionalmente por Hunt (1999) y considerada una buena especie por Arakaki et al. (2002). Esta especie está distribuida ampliamente entre Ayacucho y Apurímac .

\section{Webenbaueroceneus johnsonii F. Ritter}

$$
\text { EN, B2a; D }
$$

Publicación: Kakteen Sukk. 5:72. 1962.

Colección tipo: F. Ritter 570

Herbarios: U.

Nombre común: Desconocido.

Registro departamental: CA.

Regiones Ecológicas: MA; 3000-3500

$\mathrm{m}$.

SINAN PE: Sin registro.

Herbarios peruanos: USM (5).

Observaciones: Cactus arbustivo o arborescente, muy ramificado, hasta $9 \mathrm{~m}$ de alto que habita roquedales. W eberbauerocoreus johnsonii y W . winterianus han sido considerados sinónimos o especies muy cercanamente relacionadas. Weberbauerooereus johnstonii se encuentra en el D epartamento de Cajamarcay sus poblaciones restringidas ala localidad tipo (Chilete, San Pablo).

\section{Weberbaueroceneus longicomus $F$. Ritter}

$$
\text { EN, D }
$$

Publicación: Kakteen Sukk. 7:117. 1962. Colección tipo: F. Ritter 656

Herbarios: U.

Nombre común: D esconocido.

Registro departamental: AN, CA.

Regiones Ecológicas: MDE, MA; 2000$3000 \mathrm{~m}$.

SINANPE: Sin registro.

Hembarios penuanos: USM (7).

Observaciones: Cactus arborescente de tallos erectos, hasta $5 \mathrm{~m}$ de alto. Incluye a W eberbauerocereus albus, reportada para una localidad dudosa en el Departamento de Ancash, pero cuya presencia no ha sido confirmada. Varias poblaciones han sido observadas en las Provincias de Cajamarca y Cajabamba (valle del río Crisnejas). W eberbaueroocereus longiomus posee las flores más grandes del género (10-12 cm), con los frutos cubiertos de densos pelos lanosos.
193. Weberbauerocereus rauhii Backeb.

$$
\text { VU, B1b(iii); C2a(i) }
$$

Publicación: Descr. Cact. Nov. 27. 1956. Colección tipo: W. Rauh K-107

Herbarios: ZSS.

Nombre común: Desconocido.

Registro departamental: AR, AY, HV, IC. Regiones Ecológicas: D ST, MDE; 500$2500 \mathrm{~m}$.

SINAN PE: RPSC

Herbarios penuanos: HUSA (3), USM (4).

Observaciones: Cactus arbustivo o arbóreo, con tronco corto, hasta $6 \mathrm{~m}$ de alto. Especie cercanamente relacionada a W eberbauerooereus weberbaueri. Ambas ocupan ambientes similares, sin embargo sus rangos de distribución no se sobreponen. W eberbauerocereus rauhii se encuentra desde Pisco hasta Nazca en el Departamento de Ica, Lucanas en Ayacucho, así como en los Departamentos de Huancavelica y norte de Arequipa. Varias poblaciones han sido observadas a elevaciones bajas y medias. Las poblaciones cercanas a Pampa G aleras muestran signos de reducción en sus poblaciones y escasa presencia de individuos jóvenes, quizá debido a la extrema y creciente aridez de la zona.

\section{Weberbauerocereus torataensis F. Ritter}

$$
\text { EN, B2a }
$$

Publicación: Kakteen Sudamer. 4: 1357. 1981.

Colección tipo: F. Ritter 194

Henbarios: U.

Nombre común: D esconocido.

Registro departamental: MO.

Regiones Ecológicas: MDE; 1500-2000

m.

SINAN PE: Sin registro.

Henbarios peruanos: USM (1).

Observaciones: Esta especie está restringida a una Provincia en el D epartamento de Moquegua. Aunque puede llegar a medir hasta $1.50 \mathrm{~m}$ de alto, está caracterizada por desarrollar un hábito casi cespitoso, posee flores zigomorfas de color púrpura. W eberbauerocereus torataensis parece hibridar con 0 reocereus leuotrichus, asumiéndose como especies parentales de O reocereus tacnaesis (Charles, 2000). Si esto fuera demostrado, indicaría que la distribución de W eberbauerocereus torataensis se extiende hasta Tacna.

\section{Weberbaueroceneus weberbaueri (K. Schum. ex Vaupel) Backeb.}

\section{NT}

Publicación: Descr. Cact. Nov. 27. 1956. Colección tipo: A. Weberbauer 1413

Herbarios: B.

Nombre común: D esconocido.

Registro departamental: AR.

Regiones Ecológicas: MDE, MA; 2000$3000 \mathrm{~m}$.

SINANPE: Sin registro.

Herbarios peruanos: HUSA (15), USM (25). 
Observaciones: Cactus arbustivo, con la más amplia distribución y compleja taxonomía. Presenta una extensa historia nomenclatural, la cual se debe en parte a su alta variabilidad. Se encuentra distribuida a lo largo del D epartamento de Arequipa. Esta especie es polinizada por un murciélago, Platalina genovensium, también endémico, así como por dos especies de colibríes, si bien puede comportarse como autocompatible y autógama (Sahley, 1996). Se ha observado recientes reducciones en las poblaciones de los alrededores de la ciudad de Arequipa, por el establecimiento de nuevas urbanizaciones (Yura) o por la actividad minera.

\section{Webenbauerocereus winterianus F. Ritter}

\section{NE}

Publicación: Kakteen Sukk. 4: 54. 1961. Colección tipo: F. Ritter 165

Hemarios: U.

Nombre común: D esconocido.

Registro departamental: LL.

Regiones Ecológicas: MDE; 1000-2000

$\mathrm{m}$.

SINANPE: Sin registro.

Herbarios peruanos: USM (2).

Observaciones: Cactus arbustivo, polinizado por murciélagos. W eberbauerocereus johnsonii y W . winterianus han sido considerados sinónimos o especies muy cercanamente relacionadas. Por ello, el estatus taxonómico de W eberbauerocereus winterianus es incierto. Se conoce del Departamento de La Libertad, donde sus poblaciones están restringidas a la localidad tipo (Samne, O tuzco).

\section{X Borzipostoa mirabilis (Rauh \& Backeb.) G.D. Rowley}

Publicación: Natl. Cact. Succ. J. 37(2):47. 1982.

Colección tipo: W. Rauh 82

Herbarios:

Nombre común: D esconocido.

Registro departamental: LA.

Regiones Ecológicas: DCT; 0-500 m.

SINAN PE: Sin registro.

Henbarios peruanos: Ninguno.

Observaciones: Este taxón fue considerado por Brako \& Zarucchi (1993) como un endemismo; sin embargo, no ha sido posible evaluarlo, ni asignarle una categoría.
198. X Haagespostoa albisetata G.D. Rowley

Publicación: Natl. Cact. Succ. J. 37(3):76. 1982.

Colección tipo: Ackers s.n.

Herbarios:

Nombre común: D esconocido.

Registro departamental: LI.

Regiones Ecológicas: MDE; 1000- 2000

m.

SINAN PE: Sin registro.

Herbarios peruanos: USM (1).

Observaciones: Este taxón fue considerado por Brako \& Zarucchi (1993) como un endemismo; sin embargo, no ha sido posible evaluarlo, ni asignarle una categoría.

\section{X Haagespostoa climaxantha (Werderm.) G.D. Rowley}

Publicación: Natl. Cact. Succ. J. 37(3):76. 1982.

Colección tipo: Blossfeld 84

Herbarios:

Nombre común: D esconocido.

Registro departamental: LI.

Regiones Ecológicas: DST, MDE; 500$1500 \mathrm{~m}$

SINANPE: Sin registro.

Herbarios peruanos: Ninguno.

Observaciones: Este taxón fue considerado por Brako \& Zarucchi (1993) como un endemismo; sin embargo, no ha sido posible evaluarlo, ni asignarle una categoría. 
Mapa del Perú indicando las abreviaturas de los departamentos

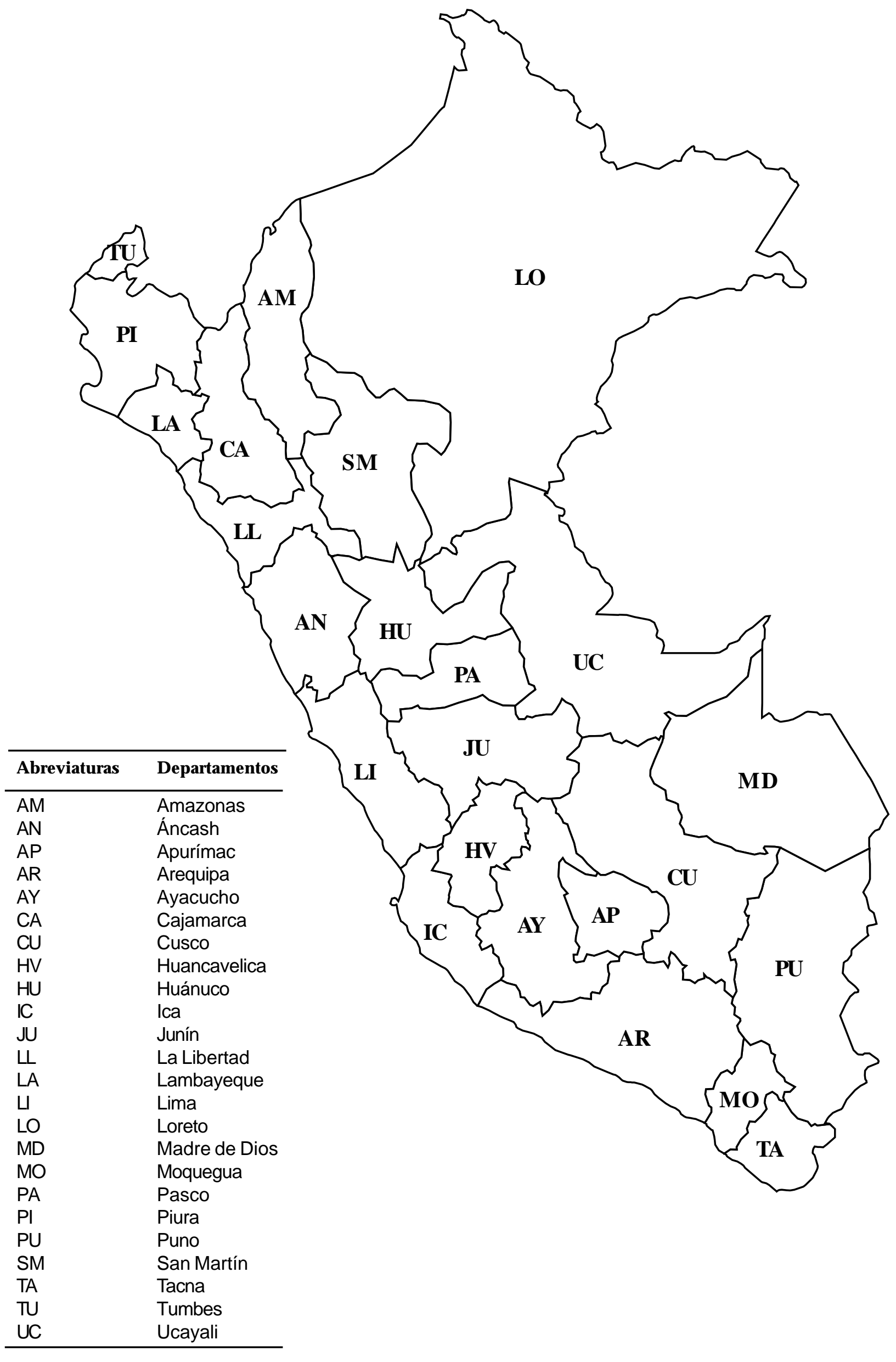

